OPEN ACCESS

Edited by:

Linda Avesani,

University of Verona, Italy

Reviewed by:

Elena Corredoira,

Instituto de Investigaciones Agrobiológicas de Galicia (IIAG),

Spain

Atanas Ivanov Atanassov, Joint Genomic Center, Bulgaria

*Correspondence: Tariq Khan

tariqkhan@uom.edu.pk tariqkhanbio@gmail.com

Mubarak Ali Khan

makhan@awkum.edu.pk

Specialty section:

This article was submitted to

Plant Biotechnology,

a section of the journal

Frontiers in Plant Science

Received: 25 September 2020 Accepted: 15 February 2021

Published: 12 March 2021

Citation:

Khan T, Khan MA, Karam K,

Ullah N, Mashwani ZUR and

Nadhman A (2021) Plant in vitro Culture Technologies; A Promise Into Factories of Secondary Metabolites Against COVID-19.

Front. Plant Sci. 12:610194 doi: $10.3389 / \mathrm{fp} / \mathrm{s} .2021 .610194$

\section{Plant in vitro Culture Technologies; A Promise Into Factories of Secondary Metabolites Against COVID-19}

\author{
Tariq Khan ${ }^{1 *}$, Mubarak Ali Khan ${ }^{2 *}$, Kashmala Karam", Nazif Ullah², \\ Zia-ur-Rehman Mashwani ${ }^{3}$ and Akhtar Nadhman ${ }^{4}$
}

${ }^{1}$ Department of Biotechnology, University of Malakand, Chakdara, Pakistan, ${ }^{2}$ Department of Biotechnology, Faculty of Chemical and Life Sciences, Abdul Wali Khan University Mardan (AWKUM), Mardan, Pakistan, ${ }^{3}$ Department of Botany, Pir Mehr Ali Shah Arid Agriculture University, Rawalpindi, Pakistan, ${ }^{4}$ Institute of Integrative Biosciences, CECOS University, Peshawar, Pakistan

The current pandemic has caused chaos throughout the world. While there are few vaccines available now, there is the need for better treatment alternatives in line with preventive measures against COVID-19. Along with synthetic chemical compounds, phytochemicals cannot be overlooked as candidates for drugs against severe respiratory coronavirus 2 (SARS-CoV-2). The important role of secondary metabolites or phytochemical compounds against coronaviruses has been confirmed by studies that reported the anti-coronavirus role of glycyrrhizin from the roots of Glycyrrhiza glabra. The study demonstrated that glycyrrhizin is a very promising phytochemical against SARS-CoV, which caused an outbreak in 2002-2003. Similarly, many phytochemical compounds (apigenin, betulonic acid, reserpine, emodin, etc.) were isolated from different plants such as Isatis indigotica, Lindera aggregate, and Artemisia annua and were employed against SARS-CoV. However, owing to the geographical and seasonal variation, the quality of standard medicinal compounds isolated from plants varies. Furthermore, many of the important medicinal plants are either threatened or on the verge of endangerment because of overharvesting for medicinal purposes. Therefore, plant biotechnology provides a better alternative in the form of in vitro culture technology, including plant cell cultures, adventitious roots cultures, and organ and tissue cultures. In vitro cultures can serve as factories of secondary metabolites/phytochemicals that can be produced in bulk and of uniform quality in the fight against COVID-19, once tested. Similarly, environmental and molecular manipulation of these in vitro cultures could provide engineered drug candidates for testing against COVID-19. The in vitro culture-based phytochemicals have an additional benefit of consistency in terms of yield as well as quality. Nonetheless, as the traditional plant-based compounds might prove toxic in some cases, engineered production of promising phytochemicals can bypass this barrier. Our article focuses on reviewing the potential of the different in vitro plant cultures to produce medicinally important secondary metabolites that could ultimately be helpful in the fight against COVID-19.

Keywords: SARS-CoV-2, COVID-19, in vitro cultures, Plants-medicinal, biotechnology, secondary metabolites 


\section{INTRODUCTION}

Severe acute respiratory syndrome coronavirus 2 (SARS-CoV-2) has become the deadliest virus in a century. SARS-CoV-2, which originated in Wuhan, China in December 2019, has killed more than two million people so far. This is the third time that a coronavirus has caused an outbreak during the 21st century, SARS and Middle East respiratory syndrome (MERS) being the previous ones. This virus has been termed the novel coronavirus (SARS-CoV-2) and causes a severe respiratory syndrome collectively called coronavirus disease 2019 (COVID-19). The disease, because of the ease of spread of its causative virus, became a pandemic very quickly. Owing to this, 2.37 million people have died because of COVID-19 and 108.33 million have tested positive for the virus as of February 13, 2021 (Worldometer, 2020).

Scientific advancements allowed researchers to advise governments across the world on quick prevention measures. Based on the rapid information coming out about the virus, including its transmission pattern, morphology, and deeper biological information, the World Health Organization (WHO) and other leading health organizations across the world advised on emergency containment and control measures. Control on a global scale allowed stakeholders from every sector to work toward mitigation measures more efficiently. Slowing down the spread and thus containment of the virus has also allowed scientists to work on many treatment options for COVID-19. Although the current option to treat COVID-19 patients is to alleviate symptoms and avoid co-infection with bacteria through medications, trials on different drug and vaccine candidates are underway (Thanh Le et al., 2020). However, the safety concerns regarding repurposed drugs and the fact that vaccines, when available, will only prevent infection, calls for additional avenues of drugs to treat patients. Plants provide one such avenue through the products of their secondary metabolism, i.e., phytochemicals. But these too are limited by safety concerns, seasonal and geographic dependence, and lesser uniformity in the metabolite profile of medicinal plants across the globe. The solution to these barriers in harnessing secondary metabolism running in plant cell factories is provided by plant biotechnology. Plant biotechnology is a very promising platform for providing uniform, safe to use, high-yield drugs against coronaviruses. This review article highlights the important potential role of plant cell factories to produce safe and high-yield medicinal compounds against COVID-19. The paper reviews the important biotechnological strategies that can be employed to make the best use of plants for providing secondary metabolites as candidates during anti-SARS-CoV-2 drug discovery.

\section{TREATMENT OF COVID-19: A BRIEF INSIGHT}

Treatment options currently explored include passive immunity (Abraham, 2020), repurposing of existing drugs, and vaccine candidates (Harrison, 2020). For instance, recently, the already available dexamethasone, an inexpensive steroidal drug has been shown to save the lives of COVID-19 patients in a trial, called RECOVERY (Ledford, 2020). Similarly, chloroquine and hydroxychloroquine, antimalarial drugs also showed impressive results when repurposed to treat COVID-19 patients (Keyaerts et al., 2004; Gautret et al., 2020; Wang et al., 2020). Vaccine trials are also underway and the Moderna biotech vaccine candidate mRNA-1273 (approved for use now by the Food and Drug Administration) which encodes the stabilized prefusion SARS-CoV-2 spike protein has provoked an immune response with no trial-limiting side effects (Jackson et al., 2020). However, vaccines, based on their very mechanism of action, only prevent a healthy individual from getting infected. Moreover, a successful vaccine is not thought, at least soon, to be available to the masses. Similarly, repurposing synthetic drugs also became controversial because of their safety concerns and adverse events (Ferner and Aronson, 2020).

The fight against COVID-19 has now become one of the greatest challenges of the current times. The pandemic has lasted for over a year now since its inception in December 2019. To date, over 90 vaccines are being developed for the COVID-19 virus by different research groups in universities and major companies. Currently, two vaccines (Pfizer-BioNTech COVID-19 vaccine and Moderna COVID-19 vaccine) have obtained emergency use authorization from the Food and Drug Administration in the United States. Pfizer and Moderna have developed messenger RNA-based vaccines that have been shown to be $90-95 \%$ effective when given at preventing doses 21 and 28 days apart, respectively (Levenson and Howard, 2020). Some of the groups are even testing the direct injection of viral proteins that will help in eliciting the immune system and developing resistance against the virus. One fascinating approach is the use of genetically modified viruses to develop coronavirus proteins in the human body. The carrier virus will act as a vector, carrying coronavirus protein sequences in its genome. Currently, measles or adenovirus (where the viruses are weakened) is used in this approach to make either replicating or non-replicating virus versions (Callaway, 2020). Another fascinating alternative is the plant-based vaccines developed by Medicago (PMI, 2020). The company is developing a Nicotiana benthamiana-based viruslike particle (VLP), to develop a potential vaccine against the coronavirus disease. The VLPs use genetic sequencing from the coronavirus to mimic it and produce an immune response in the body. Plant-based VLP technology offers a very safe alternative to the vaccines already approved or in the process of development. These vaccines are virus-free and do not rely on animal products.

\section{PLANT SECONDARY METABOLITES AND THEIR ANTIVIRAL POTENTIAL}

Plant metabolism as a factory to produce anti-SARS-CoV phytochemicals is an important area of consideration currently. It is important to highlight the antiviral potential of the main classes of plant secondary metabolites to understand the role of in vitro plant cultures and associated biotechnological manipulation in fighting SARS-CoV-2. Plants produce a diversity of organic compounds classified as primary and secondary metabolites 
based on either being directly essential to the growth and development of plants (primary metabolites) or indirectly playing their role and not essential to growth (secondary metabolites). Secondary metabolites are produced in plants in situations of intracellular and/or extracellular stress and are used for interaction with the environment and protection from pathogens. This implies that there are thousands of secondary metabolites produced in plants, classified in different classes by their chemical structures. The four major classes of plant secondary metabolites are alkaloids, glycosides, phenolics, and terpenes. The purpose of highlighting the groups of these metabolites is to relate the role these classes of compounds could play against SARS-CoV2. Several different plant-based compounds have been shown to be effective against the previous type of coronavirus, i.e., SARS$\mathrm{CoV}$. These compounds have been employed for their different mechanisms of actions against SARS-CoV (Table 1).

Alkaloids, for instance, are nitrogen-containing basic compounds and include compounds such as quinine, a bitter alkaloid isolated from the bark of the cinchona tree (Quina). A synthetic derivative of quinine, i.e., chloroquine has recently been tested and found to be a good drug candidate against SARS-CoV-2 because its DNA-intercalating properties prove potent in alleviating the symptoms of coronaviruses based on its biocompatibility (Devaux et al., 2020). Chloroquine, now being tested, has been found to result in side effects such as ventricular arrhythmias, serious cutaneous adverse reactions, and fulminant hepatic failure (Ferner and Aronson, 2020). Overall, despite the side effects, the experimentally proven efficacy of their analogs and derivatives mean that natural quinines could be effective in alleviating the symptoms based on their biocompatibility (Devaux et al., 2020). Similarly, reserpine, an alkaloid isolated from the dried root of Rauvolfia serpentina (Indian snakeroot) has been shown to inhibit the replication of SARS-CoV (the coronavirus that causes the first coronavirus-related epidemic of this century). Reserpine could thus prove to be an important candidate against SARS-CoV-2. Similarly, other important alkaloids, palmatine, and chelidonine were also reported as intercalating alkaloids and could be easily suggested as potential drug candidates against SARS-CoV-2 (Ho et al., 2007; Wink, 2020).

Similarly, flavone glycosides, phenolics, and polyphenolic compounds which are characterized by aromatic rings and hydroxyl $(-\mathrm{OH})$ groups have also demonstrated important antiviral activity in many studies. For example, three flavone glycosides, quercetin 3-O-rutinoside, kaempferol 3-O-rutinoside, and kaempferol 3-O-robinobioside have proven effective against herpes simplex virus and thus points toward their potential role in working against human viruses (Yarmolinsky et al., 2012). It has been suggested that the $-\mathrm{OH}$ groups inhibit the activity of viral proteins by forming hydrogen bonds with the positively charged amino groups of proteins. Additionally, polyphenols can intervene in the lipoprotein layers of the viral envelope and thus prevent viral entry in the host cells (Wink, 2020). For instance, the flavonoid chrysin, derived from genus Rheum and Polygonum were tested positive for their achrysinctivity against the $S$ protein and inhibition of ACE2 interaction (Ho et al., 2007). Flavonoids and polyphenolic compounds like luteolin and quercetin have experimentally proven activity against SARS-CoV. They have significantly blocked the entry of the virus into the cells. This was shown through studies of Yi et al. (2004) wherein they reported that these small molecules showed promising results with half-maximal effective concentration $\left(\mathrm{EC}_{50}\right)$ of 83.4 and $10.6 \mu \mathrm{M}$, respectively.

Essential oils and terpenoids have an equally important role as antiviral plant secondary metabolites. Essential oils can enter non-specifically into the lipid bilayer of the viral envelope, altering the fluidity of the membrane and thus interfering with its pathogenicity even before the entry of the virus (Ben-Shabat et al., 2020). Terpenoids, comprised of isoprene units, terpenes, and their oxygenated derivatives, have also proved potent against many viruses including coronaviruses. For instance, $\alpha$-cadinol, pinusolidic acid, and ferruginol, isolated from Chamaecyparis obtuse, betulonic acid, and cedrane-3 $\beta, 12$ diol, from Juniperus formosana, and cryptojaponol isolated from Cryptomeria japonica have been proven to be effective against SARS-CoV (Wen et al., 2007). The results of the study indicated that most of the terpenoids inhibited the replication of SARS-CoV at $\mathrm{EC}_{50}$ between 3.8 and $7.5 \mu \mathrm{M}$. Similarly, an important member of terpenoids, resveratrol has been shown to prevent the entry of MERS-CoV into the cell. Resveratrol fully prevented Vero E6 cell death at the concentration of 125-250 $\mu \mathrm{M}$ (Lin et al., 2017).

\section{WHY PLANT BIOTECHNOLOGY?}

While the search for anti-SARS-CoV-2 drugs is ongoing, according to Capell et al. (2020), one avenue for looking for anti-SARS-CoV-2 drugs is the plant kingdom. In the traditional setup, raw plants, as well as extracts from plants, were used to treat different diseases. The WHO has suggested that $80 \%$ of the world's population relies on plants for the treatment of many diseases (Bannerman et al., 1983). Plants have importantly been employed against human respiratory problems including respiratory viruses. Such is the importance of plant trials, that work is currently underway on dried fruit extracts of Forsythiae fructus as a part of the world's search for an effective treatment for COVID-19 (Maxmen, 2020).

However, plants face the threat of over-harvesting and thus endangerment when collected rigorously. Similarly, due to insufficient data on safety-related aspects of the use of phytomedicine, concerns are still there. There is an incorrect perception that herbal drugs are fully safe and free from any side effects. There are hundreds of toxic constituents in different plants. For this purpose, detailed insight into the pathways and products of the plant's secondary metabolism is important for drugs that are safe to use (Nature, 2020). Equally important is the fact that plants located in different regions of the world have different metabolite profiles and are highly dependent on geography and seasons. Plant biotechnology has the potential to overcome these barriers (Ramirez-Estrada et al., 2016). Plant in vitro cultures as an important pillar of plant biotechnology provides an option for making the best use of plant machinery to produce medicinally important secondary metabolites (Figure 1). 
TABLE 1 | Compounds active against SARS-CoV along with their reported anti-SARS-CoV mechanism of action.

\begin{tabular}{|c|c|c|c|c|c|c|}
\hline & Compound & Plant & Virus acting on & $I_{50}$ value & $\begin{array}{l}\text { Reported antiviral } \\
\text { mechanism }\end{array}$ & References \\
\hline 1 & Aescin & $\begin{array}{l}\text { Aesculus } \\
\text { hippocastanum }\end{array}$ & SARS-CoV & $3.4 \mu \mathrm{mol} / \mathrm{L}$ & - & Wu et al., 2004 \\
\hline 2 & Celastrol & $\begin{array}{l}\text { Tripterygium } \\
\text { regelii }\end{array}$ & SARS-COV & $10.3 \mu \mathrm{mol} / \mathrm{L}$ & Inhibits SARS-CoV 3CLpro & Ryu et al., 2010b \\
\hline 3 & Cepharanthine & $\begin{array}{l}\text { Stephania } \\
\text { japonica }\end{array}$ & SARS-CoV-2 & $0.98 \mu \mathrm{mol} / \mathrm{L}$ & ACE inhibitor & Fan et al., 2020 \\
\hline 4 & Chalcones I-IX & Angelica keiskei & SARS-COV & $11.4-129.8 \mu \mathrm{mol} / \mathrm{L}$ & $\begin{array}{l}\text { Competitively inhibits } \\
\text { SARS-CoV 3CLpro }\end{array}$ & Park et al., 2016 \\
\hline 5 & Dihydrotanshinone & Salvia miltiorrhiza & MERS-CoV & $1 \mu \mathrm{g} / \mathrm{mL}$ & - & Kim et al., 2018 \\
\hline 6 & Emodin & Rheum palmatum & SARS-CoV & $200 \mu \mathrm{mol} / \mathrm{L}$ & $\begin{array}{l}\text { Blocks the binding of } S \\
\text { protein to ACE2 }\end{array}$ & Ho et al., 2007 \\
\hline 7 & Ginsenoside-Rb1 & Panax ginseng & SARS-COV & $100 \mu \mathrm{mol} / \mathrm{L}$ & Inhibits glycoprotein activity & Wu et al., 2004 \\
\hline 8 & Glycyrrhizin & Licorice root & SARS-COV & $300 \mathrm{mg} / \mathrm{L}$ & $\begin{array}{l}\text { Upregulates nitrous oxide } \\
\text { synthase and nitrous oxide } \\
\text { production }\end{array}$ & $\begin{array}{l}\text { Cinatl et al., 2003; } \\
\text { Schoeman and } \\
\text { Fielding, } 2019\end{array}$ \\
\hline 9 & Hirsutenone & Alnus japonica & SARS-CoV & $4.1 \mu \mathrm{mol} / \mathrm{L}$ & Inhibits PLpro activity & Park et al., 2012a,b \\
\hline 10 & Iguesterin & $\begin{array}{l}\text { Tripterygium } \\
\text { regelii }\end{array}$ & SARS-CoV & $2.6 \mu \mathrm{mol} / \mathrm{L}$ & Inhibits SARS-CoV 3CLpro & Ryu et al., 2010b \\
\hline 11 & Leptodactylone & $\begin{array}{l}\text { Boenninghausenia } \\
\text { sessilicarpa }\end{array}$ & SARS-CoV & $100 \mu \mathrm{g} / \mathrm{mL}$ & - & Yang et al., 2007 \\
\hline 12 & Lycorine & Lycoris radiata & SARS-CoV & $15.7 \pm 1.2 \mathrm{nmol} / \mathrm{L}$ & - & Li et al., 2005 \\
\hline 13 & Myricetin & Myrica rubra & SARS-CoV & $2.71 \pm 0.19 \mu \mathrm{mol} / \mathrm{L}$ & Inhibits ATPase activity & Yu et al., 2012 \\
\hline 14 & Pristimererin & $\begin{array}{l}\text { Tripterygium } \\
\text { regelii }\end{array}$ & SARS-COV & $5.5 \mu \mathrm{mol} / \mathrm{L}$ & Inhibits SARS-CoV 3CLpro & Ryu et al., 2010b \\
\hline 15 & Quercetin-3- $\beta$-galactoside & Ginkgo biloba & SARS-CoV & $42.79 \pm 4.97 \mu \mathrm{mol} / \mathrm{L}$ & $\begin{array}{l}\text { Competitively inhibits } \\
\text { SARS-CoV 3CLpro }\end{array}$ & Chen et al., 2006 \\
\hline 16 & Reserpine & $\begin{array}{l}\text { Rauvolfia } \\
\text { serpentine }\end{array}$ & SARS-CoV & $6.0 \mu \mathrm{mol} / \mathrm{L}$ & - & Wu et al., 2004 \\
\hline 17 & Resveratrol & $\begin{array}{l}\text { Polygonum } \\
\text { cuspidatum }\end{array}$ & MERS-CoV & - & - & Lin et al., 2017 \\
\hline 18 & Saikosaponin $B_{2}$ & $\begin{array}{l}\text { Bupleurum } \\
\text { chinense }\end{array}$ & HCoV-229E & $1.7 \pm 0.1 \mu \mathrm{mol} / \mathrm{L}$ & $\begin{array}{l}\text { Interferes with events of } \\
\text { early viral attack }\end{array}$ & $\begin{array}{l}\text { Li et al., 2005; } \\
\text { Cheng et al., } 2006\end{array}$ \\
\hline 19 & Scutellarein & $\begin{array}{l}\text { Scutellaria } \\
\text { baicalensis }\end{array}$ & SARS-COV & $0.86 \pm 0.48 \mu \mathrm{mol} / \mathrm{L}$ & Inhibits ATPase activity & Yu et al., 2012 \\
\hline 20 & Tanshinones I-VII & Salvia miltiorrhiza & SARS-CoV & $0.7-30 \mu \mathrm{mol} / \mathrm{L}$ & Inhibits PLpro activity & Park et al., 2012b \\
\hline 21 & Tetrandrine & $\begin{array}{l}\text { Stephania } \\
\text { tetrandra }\end{array}$ & HCoV-OC43 & $0.33 \pm 0.03 \mu \mathrm{mol} / \mathrm{L}$ & Inhibits p38 MAPK pathway & Kim et al., 2019 \\
\hline 22 & Theaflavin & Black tea & SARS-CoV-2 & - & Inhibits RdRp activity & Lung et al., 2020 \\
\hline
\end{tabular}

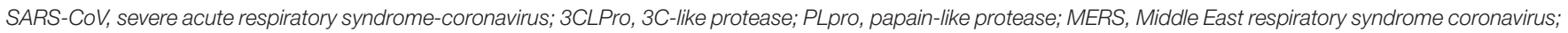

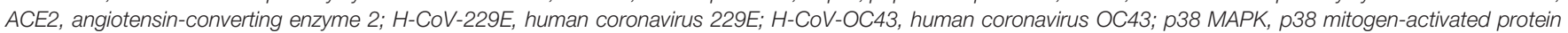
kinases; RdRp, RNA-dependent RNA polymerases.

Plant cell suspension cultures, callus cultures, hairy root cultures, adventitious root cultures, and other organ cultures can serve as the best sources of uniform production of phytomedicine for COVID-19 (Verpoorte et al., 2002). The importance of plant in vitro cultures lies in the reason that these cultures can be manipulated to trigger their defense response through activating their secondary metabolism. These triggers include elicitation by biotic and abiotic stresses given in vitro to produce enhanced quantities of phytochemicals. For instance, RamirezEstrada et al. (2016) reviewed the potential of methyl jasmonate as an important biotic elicitor to trigger the production of a diversity of secondary metabolites in different plant cell cultures (Ramirez-Estrada et al., 2016). Similarly, metabolic engineering backed by genetic manipulation tools has been a very viable biotechnology method to obtain novel metabolites and enhance the yield of the existing metabolites of interest (Gandhi et al., 2015).

\section{Micropropagation}

Micropropagation is a robust and reliable technique used for the multiplication of plants through in vitro cultures; it produces many homogeneous plants in a short period. Besides, the production of bioactive secondary metabolites can be enhanced in medicinal plants with this technique (Khan I. et al., 2020). During micropropagation, tiny parts of the plants commonly called explants excised from different plant species can be micropropagated under optimized growth conditions of culture media, temperature, and photoperiod (Abbasi et al., 2016). 


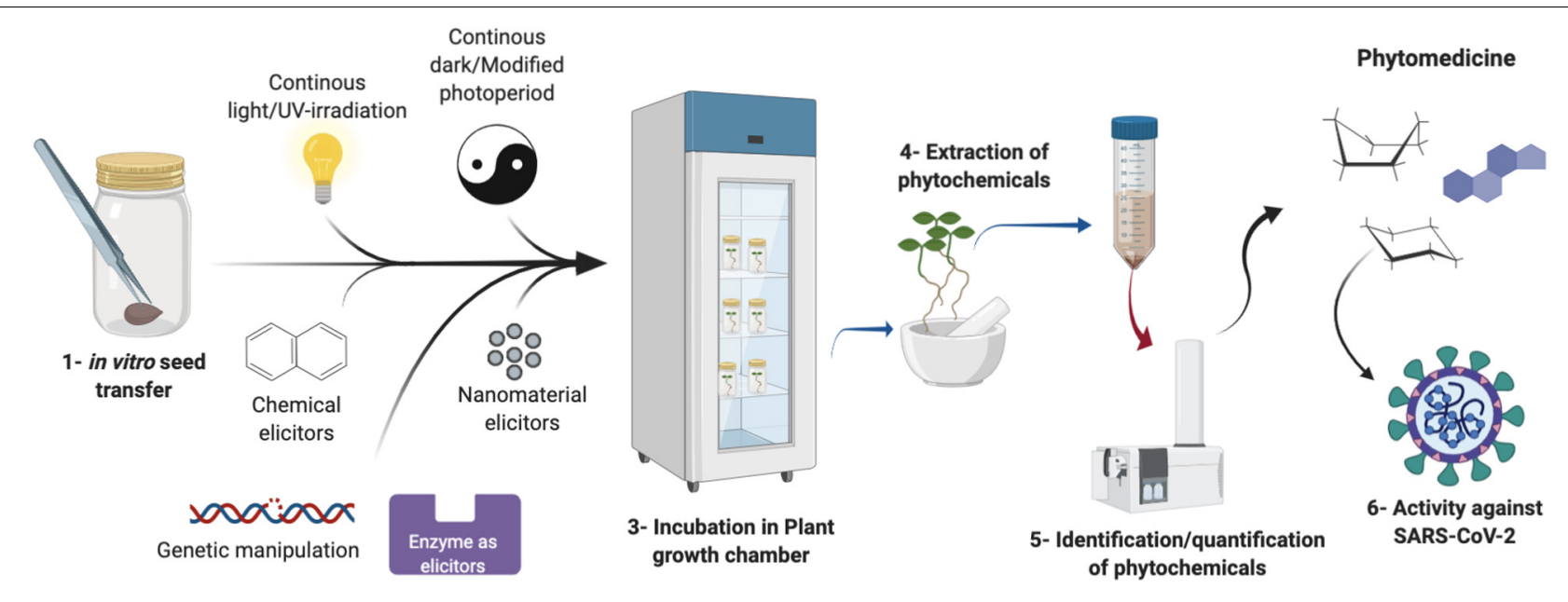

2- Biotechnological manipulation

FIGURE 1 | A schematic representation of the potential plant biotechnology methods that lead to the enhanced production of phytomedicine through in vitro cultures against SARS-CoV-2.

As indicated in Table 2, several health-promoting metabolites, especially those which are reported for a multitude of antiviral potential, have been produced in many plants through micropropagation in vitro. For instance, Santoro et al. (2013) reported the production of higher quantities of pulegone and menthofuran in Mentha piperita, when micro-propagated in vitro under the effects of 4-indol-3-ylbutyric acid (IBA) and 6benzylaminopurine (BAP).

In a recent study, Ali et al. (2018b) reported that Ajuga bracteosa (a high-valued medicinal plant) accumulated higher levels of monoterpene hydrocarbons, which could be potentially used as essential oil-based medicine against human viruses. These hydrocarbons included limonene (3.4\%), $\alpha$-pinene (5.3\%), camphene (4.45\%), $\alpha$-thujone (9.4\%), 1,8-cineole (14.3\%), borneol (11.4\%), camphor (12.2\%), and nerol (9.2) in the shoots raised in vitro in response to the application of TDZ (Ali et al., 2018a). Similarly, the supplementation of TDZ into the MS media produced a substantial amount of monoterpenes and sesquiterpenes through shoot cultures in the medicinally potent plant Lallemantia Iberica (Pourebad et al., 2015). The higher production of the important terpene volatiles (candidate anti-SARS-CoV-2 metabolites) in the regenerated shoots can be attributed to the different attributes of shoot cultures, such as the juvenile stage of the differentiated shoots, as the monoterpenes biosynthesis is directly linked to the young and immature shoot with higher metabolic potential (Bassolino et al., 2015). Biosynthesis of terpene metabolites generally takes place in epidermal cells of shoot or leaf and is stored in special glandular structures called leaf trichomes (Ali et al., 2018a). In another study, compared with callus cultures, the in vitro raised shoot cultures in medicinally important plants Lavandula angustifolia and Rosmarinus officinalis were found to accumulate higher levels of monoterpenes hydrocarbons (Gounaris, 2010). As the growth and development during in vitro shoot cultures are highly influenced by the effects of different plant growth regulators, the biosynthesis of terpenes could be correlated to in vitro growth and development. The ontogenetic changes in the shoots as a result of plant cell growth and the accelerated but controlled secondary metabolism during in vitro cultures are other important reasons which influence and regulate the biosynthesis of secondary metabolites (Khan et al., 2019a,b; Khan M. A. et al., 2020). Apart from micro-propagated plantlets many other in vitro cultures are also serving as useful sources of different medicinally important secondary metabolites (Figure 2).

\section{Callus and Cell Cultures}

Plant cell cultures compared with wild plants and other types of cultures have the advantage of being (1) less prone to various environmental variations, (2) stable production platforms of homogeneous and uniform yield, (3) rapid growth, (4) reproducible, and (5) able to synthesize novel products that do not normally exist in the native plants (Khan et al., 2017; Khan M. A. et al., 2020). In addition to medicinal products, cell suspensions have been employed to produce compounds used as fragrances, food flavors, and additives, dyes, and coloring agents (Saeed et al., 2017). A lot of important medicinal plants have been exploited for the production of useful antiviral medicinal metabolites through callus and cell cultures (Ali et al., 2018a,b). For example, as listed in Table 2, considerable levels of diosgenin (an anti-SARS-CoV metabolite) were detected in the callus cultures of Helicteres isora L (Shaikh et al., 2020). Callus and cell cultures in Gymnema sylvestre have shown an optimal production of gymnemic acid (GA) which possesses the potential to work against SARS-CoV-2 (Veerashree et al., 2012). In some studies, the cell cultures were found to only accumulate the precursors of volatile medicinal compounds; while, cultures of other plants such as mentha have been recommended to produce high-valued medicinal monoterpenes compared to those found in the intact mentha plants. Likewise, callus cultures of M. piperita have been reported for the accumulation of monoterpenes in special 
TABLE 2 | Production and enhancement of potential compounds against SARS-CoV-2 through plant biotechnological approaches.

\begin{tabular}{|c|c|c|c|c|c|c|c|c|}
\hline Serial No. & $\begin{array}{l}\text { Compound/class } \\
\text { of compounds }\end{array}$ & Plant & $\begin{array}{l}\text { In vitro } \\
\text { culture } \\
\text { type }\end{array}$ & $\begin{array}{l}\text { In vitro culture } \\
\text { conditions used }\end{array}$ & $\begin{array}{l}\text { Plant growth } \\
\text { regulator used }\end{array}$ & Elicitor used & $\begin{array}{l}\text { Remarks } \\
\text { (Results) }\end{array}$ & References \\
\hline 1 & Saponins & $\begin{array}{l}\text { Javanese ginseng } \\
\text { (Talinum } \\
\text { paniculatum) }\end{array}$ & $\begin{array}{l}\text { Adventitious } \\
\text { root } \\
\text { cultures }\end{array}$ & $\begin{array}{l}\text { Temperature } \\
25 \pm 1^{\circ} \mathrm{C} \text { in the } \\
\text { dark }\end{array}$ & $\begin{array}{l}\text { Indole-3-butyric } \\
\text { acid (IBA) or NAA } \\
\text { (1-napthaleneacetic } \\
\text { acid) }\end{array}$ & $\begin{array}{l}\text { Methyl } \\
\text { jasmonate } \\
\text { (MeJA) and } \\
\text { salicylic acid } \\
\text { (SA) }\end{array}$ & $\begin{array}{l}\text { 1.5-fold upon } \\
\text { elicitation with } \\
\text { MeJA and } \\
\text { 1.3-fold upon } \\
\text { SA }\end{array}$ & $\begin{array}{l}\text { Faizal and Sari, } \\
2019\end{array}$ \\
\hline 2 & Astragaloside (AG) & $\begin{array}{l}\text { Astragalus } \\
\text { membranaceus }\end{array}$ & $\begin{array}{l}\text { Hairy root } \\
\text { cultures }\end{array}$ & $\begin{array}{l}\text { Orbital shaker } \\
(100 \mathrm{rpm}) \text {; } \\
28 \pm 1^{\circ} \mathrm{C} \text { in the } \\
\text { dark }\end{array}$ & - & $\begin{array}{l}\text { Methyl } \\
\text { jasmonate (MJ) }\end{array}$ & $\begin{array}{l}\text { MJ-elicited } \\
(2.1 \text { - and } \\
2.0 \text {-folds } \\
\text { greater })\end{array}$ & Jiao et al., 2016 \\
\hline 3 & Diosgenin & Helicteres isora $L$. & $\begin{array}{l}\text { Callus and } \\
\text { suspension } \\
\text { cultures }\end{array}$ & $\begin{array}{l}\text { Rotatory shaker } \\
(50-60) \mathrm{rpm} ; \\
25 \pm 2^{\circ} \mathrm{C} \\
\text { temperature; } \\
40 \text { Imol } \mathrm{m}^{-2} \mathrm{~s}^{-1} \\
\text { light intensity; } \\
\text { 16/8-h light/dark } \\
\text { cycle }\end{array}$ & $\begin{array}{l}\text { 2,4- } \\
\text { dichlorophenoxyacetic } \\
\text { acid (2,4-D); kinetin } \\
\text { (Kin); and 6- } \\
\text { Benzylaminopurine } \\
\text { (BAP) }\end{array}$ & $\begin{array}{l}\text { Escherichia } \\
\text { coli; Bacillus } \\
\text { subtilis; } \\
\text { Saccharomyces } \\
\text { cerevisiae; and } \\
\text { Aspergillus } \\
\text { niger }\end{array}$ & $\begin{array}{l}\text { E. coli (1.5\%) } \\
\text { proved best } \\
\text { with a 9.1-fold } \\
\text { increase }\end{array}$ & $\begin{array}{l}\text { Shaikh et al., } \\
2020\end{array}$ \\
\hline 4 & $\begin{array}{l}\text { Gymnemic acid } \\
\text { (GA) }\end{array}$ & $\begin{array}{l}\text { Gymnema sylvestre } \\
R . B r .\end{array}$ & $\begin{array}{l}\text { Cell } \\
\text { suspension } \\
\text { cultures }\end{array}$ & $\begin{array}{l}\text { Rotatory shaker } \\
(110 \mathrm{rpm}) \text {; } \\
\text { incubator at } 25^{\circ} \mathrm{C} \\
\text { in dark; } \mathrm{pH} 5.8\end{array}$ & $\begin{array}{l}\text { 2,4- } \\
\text { dichlorophenoxyacetic } \\
\text { acid (2,4-D); } \\
\text { naphthaleneacetic } \\
\text { acid (NAA); } \\
\text { 6-benzyladenine } \\
\text { (BA); picloram }\end{array}$ & $\begin{array}{l}\text { Methyl } \\
\text { jasmonate (MJ); } \\
\text { yeast extract; } \\
\text { chitin; and } \\
\text { pectin }\end{array}$ & $\begin{array}{l}\text { Yeast extract } \\
\text { (5.25-folds); MJ } \\
\text { (2.8-folds); } \\
\text { pectin } \\
\text { (2.65-folds); } \\
\text { while chitin } \\
\text { (2.62-folds) }\end{array}$ & $\begin{array}{l}\text { Veerashree } \\
\text { et al., } 2012\end{array}$ \\
\hline 5 & Flavonoid & Isatis tinctoria $L$. & $\begin{array}{l}\text { Hairy root } \\
\text { cultures }\end{array}$ & $\begin{array}{l}\text { Temperature } 30^{\circ} \mathrm{C} \text {; } \\
\mathrm{pH} 7.0 \text {; and time } \\
72 \mathrm{~h}\end{array}$ & - & $\begin{array}{l}\text { Aspergillus } \\
\text { niger and } \\
\text { Aspergillus } \\
\text { oryzae }\end{array}$ & $\begin{array}{l}\text { 6.83-fold } \\
\text { increase }\end{array}$ & Jiao et al., 2018 \\
\hline 6 & Rosmarinic acid & $\begin{array}{l}\text { Purple basil } \\
\text { (Ocimum basilicum } \\
\text { L. var. purpurascen) }\end{array}$ & $\begin{array}{l}\text { Callus } \\
\text { cultures }\end{array}$ & $\begin{array}{l}\text { Temperature } \\
\left(25 \pm 2^{\circ} \mathrm{C}\right) ; \mathrm{pH} \text { of } \\
5.6-5.7 ; 16 / 8 \mathrm{~h} \\
\text { light/dark }\end{array}$ & $\begin{array}{l}\text { Naphthaleneacetic } \\
\text { acid (NAA) }\end{array}$ & $\begin{array}{l}\text { Melatonin; and } \\
\text { UV-C } \\
\text { irradiations }\end{array}$ & $\begin{array}{l}\text { Melatonin } \\
\text { (1.4-fold); UV-C } \\
\text { radiations } \\
\text { (2.3-fold) } \\
\text { elevation }\end{array}$ & $\begin{array}{l}\text { Nazir et al., } \\
2020\end{array}$ \\
\hline 7 & Glycyrrhizin & $\begin{array}{l}\text { Glycyrrhiza glabra } \\
\text { L. }\end{array}$ & $\begin{array}{l}\text { Hairy root } \\
\text { cultures }\end{array}$ & $\begin{array}{l}\text { Temperature } \\
28 \pm 2^{\circ} \mathrm{C} ; 60 \mu \\
\mathrm{mol} \text { photon } \mathrm{m}^{-2} \\
\mathrm{~s}^{-1} \text { light for } 16 \mathrm{~h} \\
\text { day and } 8 \mathrm{~h} \text { dark }\end{array}$ & $\begin{array}{l}\text { Indole-3-acetic acid } \\
\text { (IAA) }\end{array}$ & $\begin{array}{l}\text { Abiotic elicitors: } \\
\text { polyethylene } \\
\text { glycol (PEG); } \\
\text { CdCl2 Biotic } \\
\text { elicitor: } \\
\text { cellulase; } \\
\text { mannan }\end{array}$ & $\begin{array}{l}\text { PEG enhanced } \\
\text { the yield up to } \\
\text { 5.4-folds; } \\
\text { cellulase } \\
\text { (8.6-folds); } \\
\text { Mannan } \\
\text { (7.8-folds) }\end{array}$ & $\begin{array}{l}\text { Srivastava } \\
\text { et al., } 2019\end{array}$ \\
\hline
\end{tabular}


TABLE 2 | Continued

\begin{tabular}{|c|c|c|c|c|c|c|c|c|}
\hline Serial No. & $\begin{array}{l}\text { Compound/class } \\
\text { of compounds }\end{array}$ & Plant & $\begin{array}{l}\text { In vitro culture } \\
\text { type }\end{array}$ & $\begin{array}{l}\text { In vitro culture } \\
\text { conditions used }\end{array}$ & $\begin{array}{l}\text { Plant growth } \\
\text { regulator used }\end{array}$ & Elicitor used & $\begin{array}{l}\text { Remarks } \\
\text { (Results) }\end{array}$ & References \\
\hline 8 & Chicoric acid & $\begin{array}{l}\text { Purple basil } \\
\text { (Ocimum basilicum } \\
\text { L. var. } \\
\text { purpurascens) }\end{array}$ & Callus cultures & $\begin{array}{l}\text { Temperature } \\
\left(25 \pm 2^{\circ} \mathrm{C} ; \mathrm{pH} \text { of }\right. \\
5.6-5.7 ; 16 / 8 \mathrm{~h} \\
\text { light/dark }\end{array}$ & $\begin{array}{l}\text { Naphthaleneacetic } \\
\text { acid (NAA) }\end{array}$ & $\begin{array}{l}\text { Melatonin and } \\
\text { UV-C } \\
\text { irradiations }\end{array}$ & $\begin{array}{l}\text { Melatonin } \\
\text { ( } 3.2 \text {-folds) and } \\
\text { UV-C radiations } \\
\text { (4.1-folds) }\end{array}$ & $\begin{array}{l}\text { Nazir et al., } \\
2020\end{array}$ \\
\hline 9 & Quercetin & Abutilon indicum L. & Callus cultures & $\begin{array}{l}\text { Temperature } 25^{\circ} \mathrm{C} \text {; } \\
\text { pH } 5.75 \text { under dark } \\
\text { conditions }\end{array}$ & $\begin{array}{l}\text { 2,4-dichloro } \\
\text { phenoxy acetic } \\
\text { acid }(2,4-D) \text { with } \\
\text { indole-3-acetic acid } \\
\text { (IAA) }\end{array}$ & $\begin{array}{l}\text { phenylalanine } \\
\text { (PA) }\end{array}$ & $\begin{array}{l}\text { Three-fold } \\
\text { increase }\end{array}$ & $\begin{array}{l}\text { Sajjalaguddam } \\
\text { and Paladugu, } \\
2015\end{array}$ \\
\hline 10 & Peonidin & $\begin{array}{l}\text { Purple basil } \\
\text { (Ocimum basilicum } \\
\text { L. var. } \\
\text { purpurascens) }\end{array}$ & Callus cultures & $\begin{array}{l}\text { Temperature } \\
25 \pm 2^{\circ} \mathrm{C} ; \mathrm{pH} \text { of } \\
5.6-5.7 ; 16 / 8 \mathrm{~h} \\
\text { light/dark }\end{array}$ & $\begin{array}{l}\text { Naphthaleneacetic } \\
\text { acid (NAA) }\end{array}$ & $\begin{array}{l}\text { Melatonin and } \\
\text { UV-C radiations }\end{array}$ & $\begin{array}{l}\text { Melatonin } \\
(2.0 \text {-fold); and } \\
\text { UV-C radiations } \\
\text { ( } 2.7 \text {-fold) }\end{array}$ & Jiao et al., 2018 \\
\hline 11 & Kaempferol & $\begin{array}{l}\text { Dysosma pleiantha } \\
\text { (Hance) Woodson }\end{array}$ & Callus cultures & $\begin{array}{l}\text { Temperature } \\
25 \pm 1^{\circ} \mathrm{C} ; \mathrm{pH} \\
5.6-5.816 \mathrm{H} \\
\text { photoperiod from } \\
\text { white fluorescent } \\
\text { lamps at a light } \\
\text { intensity of } 43 \mu \mathrm{mol} \\
\mathrm{m}^{-2} \mathrm{~S}^{-1} / 8 \mathrm{~h} \text { dark } \\
\text { cycle }\end{array}$ & $\begin{array}{l}\text { Medium (B5) 2,4- } \\
\text { dichlorophenoxyacetic } \\
\text { acid (2,4-D); kinetin }\end{array}$ & $\begin{array}{l}\text { Casein hydro } \\
\text { lysate; coconut } \\
\text { water; and } \\
\text { peptone extract }\end{array}$ & $\begin{array}{l}\text { 12.39-folds } \\
\text { enhancement }\end{array}$ & $\begin{array}{l}\text { Karuppaiya and } \\
\text { Tsay, } 2020\end{array}$ \\
\hline 12 & Ephedrine & Ephedra alata & $\begin{array}{l}\text { Suspension } \\
\text { cultures }\end{array}$ & $\begin{array}{l}\text { Temperature } \\
25 \pm 2^{\circ} \mathrm{C} ; \mathrm{pH} \\
5.7-5.8 \text {; fluorescent } \\
\text { light } \\
\text { (2500-3000 lux); } \\
\text { 16-h photoperiod }\end{array}$ & $\begin{array}{l}\text { 2,4- } \\
\text { dichlorophenoxy } \\
\text { acetic acid (2,4-D); } \\
\text { and kinetin (Kn) }\end{array}$ & $\begin{array}{l}\text { Aspergillus } \\
\text { niger and yeast } \\
\text { extract }\end{array}$ & $\begin{array}{l}\text { Seven-fold } \\
\text { increase }\end{array}$ & $\begin{array}{l}\text { Hegazi et al., } \\
2020\end{array}$ \\
\hline 13 & Caffeic acid & $\begin{array}{l}\text { Vitex agnus castus } \\
\text { L. }\end{array}$ & $\begin{array}{l}\text { Agitated shoot } \\
\text { cultures }\end{array}$ & $\begin{array}{l}\text { Rotary shaker at } \\
140 \mathrm{rpm}\end{array}$ & $\begin{array}{l}\text { Naphthaleneacetic } \\
\text { acid (NAA); benzyl } \\
\text { aminopurine (BAP); } \\
\text { gibberellic acid } \\
\text { (GA3) }\end{array}$ & L-phenylalanine & $\begin{array}{l}1.5 \text {-folds } \\
\text { increase }\end{array}$ & $\begin{array}{l}\text { Skrzypczak- } \\
\text { Pietraszek } \\
\text { et al., } 2018\end{array}$ \\
\hline 14 & Chlorogenic acid & Cecropia obtusifolia & $\begin{array}{l}\text { Callus and cell } \\
\text { suspension cultures }\end{array}$ & $\begin{array}{l}\text { Rotatory shaker at } \\
110 \mathrm{rpm} \text {; } \\
\text { temperature } 26^{\circ} \mathrm{C} \text {; } \\
\text { photoperiod of } \\
16 \text {-h light with cool } \\
\text { white fluorescent } \\
\text { lamps at } 50 \mathrm{IMm}^{-2} \\
\mathrm{~s}^{-1}\end{array}$ & $\begin{array}{l}\text { Naphthalene acetic } \\
\text { acid (NAA); 2,4- } \\
\text { dichlorophenoxyacetic } \\
\text { acid (2,4-D); } \\
\text { indole-3-butyric } \\
\text { acid (IBA); and } \\
\text { indole-3-acetic acid } \\
\text { (IAA); 6- } \\
\text { benzylaminopurine } \\
\text { (BAP) }\end{array}$ & $\begin{array}{l}\text { Nitrate } \\
\text { deficiency } \\
\text { (lacking } \\
\text { ammonium) }\end{array}$ & $\begin{array}{l}7.7 \text {-fold } \\
\text { increase }\end{array}$ & $\begin{array}{l}\text { Del Pilar } \\
\text { Nicasio-Torres } \\
\text { et al., } 2012\end{array}$ \\
\hline
\end{tabular}


TABLE 2 | Continued

\begin{tabular}{|c|c|c|c|c|c|c|c|c|}
\hline Serial No. & $\begin{array}{l}\text { Compound/class } \\
\text { of compounds }\end{array}$ & Plant & $\begin{array}{l}\text { In vitro culture } \\
\text { type }\end{array}$ & $\begin{array}{l}\text { In vitro culture } \\
\text { conditions used }\end{array}$ & $\begin{array}{l}\text { Plant growth } \\
\text { regulator used }\end{array}$ & Elicitor used & $\begin{array}{l}\text { Remarks } \\
\text { (Results) }\end{array}$ & References \\
\hline 15 & Glycyrrhetinic acid & $\begin{array}{l}\text { Taverniera } \\
\text { cuneifolia (Roth) } \\
\text { Arn }\end{array}$ & Root cultures & 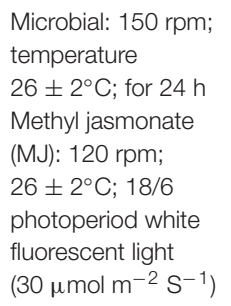 & - & $\begin{array}{l}\text { Microbial } \\
\text { elicitation } \\
\text { (fungal and } \\
\text { bacterial); } \\
\text { methyl } \\
\text { jasmonate (MJ) }\end{array}$ & $\begin{array}{l}\text { Microbial } \\
\text { elicitation } \\
\text { (three-folds); } \\
\text { methyl } \\
\text { jasmonate (2.5) } \\
\text { enhancement }\end{array}$ & $\begin{array}{l}\text { Awad et al., } \\
2014\end{array}$ \\
\hline 16 & Matairesinol & Forsythia $\times$ intermedia & $\begin{array}{l}\text { Cell suspension } \\
\text { cultures }\end{array}$ & $\begin{array}{l}\text { Gyratory shaker at } \\
110 \mathrm{rpm} ; 25^{\circ} \mathrm{C} \text {; in } \\
\text { the dark }\end{array}$ & - & $\begin{array}{l}\text { Methyl } \\
\text { jasmonate and } \\
\text { coniferyl } \\
\text { alcohol }\end{array}$ & $\begin{array}{l}\text { Seven-fold } \\
\text { increase }\end{array}$ & $\begin{array}{l}\text { Schmitt and } \\
\text { Petersen, } 2002\end{array}$ \\
\hline 17 & Lignans & $\begin{array}{l}\text { Linum } \\
\text { ussitatsimum L }\end{array}$ & $\begin{array}{l}\text { Cell suspension } \\
\text { cultures }\end{array}$ & $\begin{array}{l}\text { Gyratory shaker at } \\
100 \text { rpm placed in } \\
\text { optimum conditions }\end{array}$ & $\begin{array}{l}\text { Naphthalene acetic } \\
\text { acid (NAA) }\end{array}$ & $\begin{array}{l}\text { Salicylic acid } \\
\text { (SA) }\end{array}$ & $\begin{array}{l}2.7 \text {-fold } \\
\text { increase }\end{array}$ & $\begin{array}{l}\text { Nadeem et al., } \\
2019\end{array}$ \\
\hline 18 & $\begin{array}{l}\text { Neochlorogenic } \\
\text { acid }\end{array}$ & $\begin{array}{l}\text { Vitex agnus castus } \\
\text { L. }\end{array}$ & $\begin{array}{l}\text { Agitated shoot } \\
\text { cultures }\end{array}$ & $\begin{array}{l}\text { Rotary shaker at } \\
140 \mathrm{rpm}\end{array}$ & $\begin{array}{l}\alpha \text {-naphthaleneacetic } \\
\text { acid (NAA); } \\
\text { benzylaminopurine } \\
\text { (BAP); gibberellic } \\
\text { acid (GA3) }\end{array}$ & L-phenylalanine & 16-fold & $\begin{array}{l}\text { Skrzypczak- } \\
\text { Pietraszek } \\
\text { et al., } 2018\end{array}$ \\
\hline 19 & $\begin{array}{l}\text { Neolignans } \\
\text { (dehydrodiconiferyl) }\end{array}$ & $\begin{array}{l}\text { Linum } \\
\text { ussitatsimum L }\end{array}$ & $\begin{array}{l}\text { Cell suspension } \\
\text { cultures }\end{array}$ & $\begin{array}{l}\text { Gyratory shaker at } \\
100 \text { rpm with } \\
\text { optimum growth } \\
\text { conditions }\end{array}$ & $\begin{array}{l}\text { Naphthalene acetic } \\
\text { acid (NAA) }\end{array}$ & Salicylic acid & 3.88-fold & $\begin{array}{l}\text { Nadeem et al., } \\
2019\end{array}$ \\
\hline 20 & p-coumaric acid & $\begin{array}{l}\text { Vitex agnus castus } \\
\text { L. }\end{array}$ & $\begin{array}{l}\text { Agitated shoot } \\
\text { cultures }\end{array}$ & $\begin{array}{l}\text { Rotary shaker at } \\
140 \mathrm{rpm}\end{array}$ & $\begin{array}{l}\alpha \text {-naphthaleneacetic } \\
\text { acid (NAA); } \\
\text { benzylaminopurine } \\
\text { (BAP); gibberellic } \\
\text { acid (GA3) }\end{array}$ & L-phenylalanine & 5.3-fold & $\begin{array}{l}\text { Skrzypczak- } \\
\text { Pietraszek } \\
\text { et al., } 2018\end{array}$ \\
\hline 21 & (-) Menthone & $\begin{array}{l}\text { Peppermint } \\
\text { (Mentha piperita) }\end{array}$ & Micro propagation & $\begin{array}{l}\text { Temperature } \\
22 \pm 2^{\circ} \mathrm{C} ; \mathrm{pH} \\
5.6-5.8 \text {; relative } \\
\text { humidity ( 70\%); } \\
\text { light ( } 16 / 8 \mathrm{~h} \\
\text { light/dark cycle) }\end{array}$ & $\begin{array}{l}\text { Auxins } \\
\text { 4-indole-3-ylbutyric } \\
\text { acid (IBA); and the } \\
\text { cytokinins 6- } \\
\text { benzylaminopurine } \\
\text { (BAP) }\end{array}$ & - & $\begin{array}{l}\text { Two-fold } \\
\text { increase }\end{array}$ & $\begin{array}{l}\text { Santoro et al., } \\
2013\end{array}$ \\
\hline 22 & Cynaroside & $\begin{array}{l}\text { Vitex agnus castus } \\
L \text {. }\end{array}$ & $\begin{array}{l}\text { Agitated shoot } \\
\text { cultures }\end{array}$ & $\begin{array}{l}\text { Rotary shaker at } \\
140 \mathrm{rpm}\end{array}$ & $\begin{array}{l}\alpha \text {-naphthaleneacetic } \\
\text { acid (NAA); } \\
\text { benzylaminopurine } \\
\text { (BAP); gibberellic } \\
\text { acid (GA3) }\end{array}$ & L-phenylalanine & 1.5 -fold & $\begin{array}{l}\text { Skrzypczak- } \\
\text { Pietraszek } \\
\text { et al., } 2018\end{array}$ \\
\hline
\end{tabular}


TABLE 2 | Continued

\begin{tabular}{|c|c|c|c|c|c|c|c|c|}
\hline Serial No. & $\begin{array}{l}\text { Compound/class } \\
\text { of compounds }\end{array}$ & Plant & $\begin{array}{l}\text { In vitro culture } \\
\text { type }\end{array}$ & $\begin{array}{l}\text { In vitro culture } \\
\text { conditions used }\end{array}$ & $\begin{array}{l}\text { Plant growth } \\
\text { regulator used }\end{array}$ & Elicitor used & $\begin{array}{l}\text { Remarks } \\
\text { (Results) }\end{array}$ & References \\
\hline 23 & (+)-Pulegone & $\begin{array}{l}\text { Peppermint } \\
\text { (Mentha piperita) }\end{array}$ & Micro propagation & $\begin{array}{l}\text { Temperature } \\
22 \pm 2^{\circ} \mathrm{C} \text {; } \mathrm{pH} \\
5.6-5.8 \text {; relative } \\
\text { humidity }(\sim 70 \%) ; \\
\text { light }(16 / 8 \mathrm{~h} \\
\text { light/dark cycle) }\end{array}$ & $\begin{array}{l}\text { Auxins } \\
\text { 4-indole-3-ylbutyric } \\
\text { acid (IBA); and the } \\
\text { cytokinins 6- } \\
\text { benzylaminopurine } \\
\text { (BAP) }\end{array}$ & - & $\begin{array}{l}\text { Three-fold } \\
\text { increase }\end{array}$ & $\begin{array}{l}\text { Santoro et al., } \\
2013\end{array}$ \\
\hline 24 & Limonene & $\begin{array}{l}\text { Pennyroyal (Mentha } \\
\text { pulegium) }\end{array}$ & $\begin{array}{l}\text { Cell suspension } \\
\text { cultures }\end{array}$ & $\begin{array}{l}\text { Shaker with } 100 \\
\text { round per minute in } \\
25 \pm 1^{\circ} \mathrm{C}\end{array}$ & $2,4-D$ & $\begin{array}{l}\text { Yeast extract; } \\
\text { salicylic acid }\end{array}$ & $\begin{array}{l}\text { Limonene } \\
\text { increased with } \\
\text { increasing } \\
\text { concentrations } \\
\text { of yeast extract } \\
\text { elicitor }\end{array}$ & $\begin{array}{l}\text { Darvishi et al., } \\
2016\end{array}$ \\
\hline 25 & (+)-menthofuran & $\begin{array}{l}\text { Peppermint } \\
\text { (Mentha piperita) }\end{array}$ & Micro propagation & $\begin{array}{l}\text { Temperature } \\
22^{\circ} \mathrm{C} \pm 2^{\circ} \mathrm{C} \text {; } \mathrm{pH} \\
5.6-5.8 \text {; relative } \\
\text { humidity }(\sim 70 \%) ; \\
\text { light (16/8 } \mathrm{h} \\
\text { light/dark cycle) }\end{array}$ & $\begin{array}{l}\text { Auxins } \\
\text { 4-indole-3-ylbutyric } \\
\text { acid (IBA); and the } \\
\text { cytokinins 6- } \\
\text { benzylaminopurine } \\
\text { (BAP) }\end{array}$ & - & $\begin{array}{l}\text { Two-fold } \\
\text { enhancement }\end{array}$ & $\begin{array}{l}\text { Santoro et al., } \\
2013\end{array}$ \\
\hline 26 & Isoorientin (ISO) & Cecropia obtusifolia & $\begin{array}{l}\text { Cell suspension } \\
\text { cultures }\end{array}$ & $\begin{array}{l}\text { Rotatory shaker at } \\
110 \mathrm{rpm} \text {; } \\
\text { temperature } 26^{\circ} \mathrm{C} \text {; } \\
\text { photoperiod of } \\
16 \text {-h light with cool } \\
\text { white fluorescent } \\
\text { lamps at } 50 \mathrm{IMm}^{-2} \\
\mathrm{~s}^{-1}\end{array}$ & $\begin{array}{l}\text { Naphthalene acetic } \\
\text { acid (NAA); 2,4- } \\
\text { dichlorophenoxyacetic } \\
\text { acid (2,4-D); } \\
\text { indole-3-butyric } \\
\text { acid (IBA); } \\
\text { indole-3-acetic acid } \\
\text { (IAA); 6- } \\
\text { benzylaminopurine } \\
\text { (BAP) }\end{array}$ & $\begin{array}{l}\text { Nitrate } \\
\text { deficiency } \\
\text { (lacking } \\
\text { ammonium) }\end{array}$ & $\begin{array}{l}\text { ISO synthesis } \\
\text { was induced } \\
\text { earlier and for } \\
\text { longer time } \\
\text { period }\end{array}$ & $\begin{array}{l}\text { Del Pilar } \\
\text { Nicasio-Torres } \\
\text { et al., } 2012\end{array}$ \\
\hline 27 & Gallic acid & $\begin{array}{l}\text { Barringtonia } \\
\text { racemosa } L \text {. }\end{array}$ & $\begin{array}{l}\text { Cell suspension } \\
\text { cultures }\end{array}$ & $\begin{array}{l}25 \pm 2^{\circ} \mathrm{C} \text { under } \\
18 \mathrm{~h} \mathrm{light} \text { and } 6 \mathrm{~h} \\
\text { dark }\end{array}$ & 2,4-D and kinetin & $\begin{array}{l}\text { Biotic } \\
\text { (chitosan); } \\
\text { abiotic (silver } \\
\text { nitrate) }\end{array}$ & $\begin{array}{l}\text { 2.64-fold (silver } \\
\text { nitrate); } \\
\text { 1.34-fold } \\
\text { (chitosan) } \\
\text { increase }\end{array}$ & $\begin{array}{l}\text { Osman et al., } \\
2018\end{array}$ \\
\hline 28 & Aloe-Emodin & Cassia tora & Root cultures & $\begin{array}{l}\text { Shaking at } 60 \mathrm{rpm} ; \\
25 \pm 2^{\circ} \mathrm{C} \text {; in dark } \\
\text { conditions }\end{array}$ & $\begin{array}{l}\text { 1- } \\
\text { naphthaleneacetic } \\
\text { acid and kinetin }\end{array}$ & $\begin{array}{l}\text { Chitosan; yeast } \\
\text { extract }\end{array}$ & $\begin{array}{l}\text { Chitosan ( } 8.82 \\
\text { times); yeast } \\
\text { extract ( } 6.21 \\
\text { times) }\end{array}$ & $\begin{array}{l}\text { Teptat et al., } \\
2020\end{array}$ \\
\hline 29 & Rosin & $\begin{array}{l}\text { Rhodiola rosea } \\
\text { (rose root) }\end{array}$ & $\begin{array}{l}\text { Compact callus } \\
\text { aggregate cultures }\end{array}$ & $\begin{array}{l}\text { Shaken at } \\
14.14 \mathrm{rad} \mathrm{s}^{-1} \\
(135 \mathrm{rpm})\end{array}$ & $\begin{array}{l}\text { MS-Rh media } \\
\text { supplemented with } \\
6- \\
\text { benzylaminopurine } \\
\text { (BAP); naphthalene } \\
\text { acetic acid (NAA); } \\
\text { sucrose }\end{array}$ & $\begin{array}{l}\text { Cinnamyl } \\
\text { alcohol }\end{array}$ & $\begin{array}{l}3 \text { to } 6 \text {-fold } \\
\text { increase }\end{array}$ & $\begin{array}{l}\text { György et al., } \\
2004\end{array}$ \\
\hline
\end{tabular}


TABLE 2 | Continued

\begin{tabular}{|c|c|c|c|c|c|c|c|c|}
\hline Serial No. & $\begin{array}{l}\text { Compound/class } \\
\text { of compounds }\end{array}$ & Plant & $\begin{array}{l}\text { In vitro culture } \\
\text { type }\end{array}$ & $\begin{array}{l}\text { In vitro culture } \\
\text { conditions used }\end{array}$ & $\begin{array}{l}\text { Plant growth } \\
\text { regulator used }\end{array}$ & Elicitor used & $\begin{array}{l}\text { Remarks } \\
\text { (Results) }\end{array}$ & References \\
\hline 30 & Salidroside & $\begin{array}{l}\text { Rhodiola imbricata } \\
\text { Edgew. }\end{array}$ & $\begin{array}{l}\text { Callus and } \\
\text { suspension cultures }\end{array}$ & $\begin{array}{l}100 \mathrm{rpm} \text { shaker for } \\
8 \mathrm{~h} \text { and kept static } \\
\text { for } 16 \mathrm{~h} \text {; } \mathrm{pH} 5.7\end{array}$ & $\begin{array}{l}\text { Indole-3-butyric } \\
\text { acid (IBA); 6- } \\
\text { Benzylaminopurine } \\
\text { (BAP); gibberellic } \\
\text { acid (GA3); kinetin } \\
\text { (KN) and } \\
\text { Thidiazuron (TDZ) }\end{array}$ & $\begin{array}{l}\text { Chemical } \\
\text { elicitors (growth } \\
\text { hormones); } \\
\text { physical } \\
\text { elicitors } \\
\text { (photosynthetic } \\
\text { lights, } \\
\text { ultraviolet light) }\end{array}$ & 5.35-fold & Kad et al., 2018 \\
\hline 31 & Scopoletin & $\begin{array}{l}\text { Spilanthes acmella } \\
\text { Murr. }\end{array}$ & $\begin{array}{l}\text { Cell Suspension } \\
\text { cultures }\end{array}$ & $\begin{array}{l}\text { Rotary shaker at } \\
100 \pm 10 \mathrm{rpm} ; \\
25 \pm 2^{\circ} \mathrm{C} ; 16-8 \mathrm{~h} \\
\text { light-dark regime, } \\
\text { using fluorescent } \\
\text { lamps at a light } \\
\text { intensity of } 35 \mu \\
\mathrm{mol} \mathrm{m}^{2} \mathrm{~s}^{-1}\end{array}$ & $\begin{array}{l}\text { 6-benzyladenine; } \\
\text { 2,4- } \\
\text { dichlorophenoxyacetic } \\
\text { acid }\end{array}$ & $\begin{array}{l}\text { Casein } \\
\text { hydrolysate and } \\
\text { L-phenylalanine }\end{array}$ & $\begin{array}{l}\text { 1.39-fold } \\
\text { (casein } \\
\text { hydrolysate); } \\
\text { 3.43-fold (L- } \\
\text { phenylalanine) }\end{array}$ & $\begin{array}{l}\text { Abyari et al., } \\
2016\end{array}$ \\
\hline 32 & Tyrosol & Rhodiola crenulata & $\begin{array}{l}\text { Cell suspension } \\
\text { cultures }\end{array}$ & $\begin{array}{l}\text { Rotary shaker at } \\
120 \mathrm{rpm} \text {; } \\
25 \pm 1^{\circ} \mathrm{C} \text {; light } \\
\text { intensity } \\
24 \mathrm{Imo} / \mathrm{m}^{2} / \mathrm{s} ; 16 \mathrm{~h} \\
\text { light photoperiod }\end{array}$ & $\begin{array}{l}\text { 6-benzyaldenine } \\
\text { (BA); naphthalene } \\
\text { acetic acid (NAA) } \\
\text { and thidiazuron } \\
\text { (TDZ) }\end{array}$ & - & $\begin{array}{l}\text { High level of } \\
\text { tyrosol were } \\
\text { detected }\end{array}$ & Shi et al., 2013 \\
\hline 33 & Wogonin & Scutellaria lateriflora & Hairy root cultures & $\begin{array}{l}\text { Shaking (121 rpm) } \\
\text { at } 26 \pm 1^{\circ} \mathrm{C}\end{array}$ & $\begin{array}{l}\text { Phytohormone-free } \\
\text { MS medium having } \\
\text { sucrose and } \\
\text { supplemented with } \\
\text { antibiotic ampicillin } \\
\text { and cefotaxim }\end{array}$ & $\begin{array}{l}\text { YE and } \\
\text { bacterial } \\
\text { suspensions (A) } \\
\text { A. rhizogenes } \\
\text { A4, (B) } \\
\text { Pectobacterium } \\
\text { carotovorum } \\
1043 \text { (Pba } \\
\text { 1043), (C) } \\
\text { Pseudomonas } \\
\text { syringae var. } \\
\text { syringae 764 } \\
\text { (Pss 764), (D) } \\
\text { Klebsiella } \\
\text { pneumoniae } \\
\text { 3896, and (E) } \\
\text { Enterobacter } \\
\text { sakazakii }\end{array}$ & $\begin{array}{l}\text { 4.4-fold } \\
\text { increase }\end{array}$ & $\begin{array}{l}\text { Wilczañska- } \\
\text { Barska et al., } \\
2012\end{array}$ \\
\hline
\end{tabular}


TABLE 2 | Continued

\begin{tabular}{|c|c|c|c|c|c|c|c|c|}
\hline Serial No. & $\begin{array}{l}\text { Compound/class } \\
\text { of compounds }\end{array}$ & Plant & $\begin{array}{l}\text { In vitro culture } \\
\text { type }\end{array}$ & $\begin{array}{l}\text { In vitro culture } \\
\text { conditions used }\end{array}$ & $\begin{array}{l}\text { Plant growth } \\
\text { regulator used }\end{array}$ & Elicitor used & $\begin{array}{l}\text { Remarks } \\
\text { (Results) }\end{array}$ & References \\
\hline 34 & Rutin & $\begin{array}{l}\text { Vitex agnus castus } \\
\text { L. }\end{array}$ & $\begin{array}{l}\text { Agitated shoot } \\
\text { cultures }\end{array}$ & $\begin{array}{l}\text { Rotary shaker at } \\
140 \mathrm{rpm}\end{array}$ & $\begin{array}{l}\alpha \text {-naphthaleneacetic } \\
\text { acid (NAA); } \\
\text { benzylaminopurine } \\
\text { (BAP); gibberellic } \\
\text { acid (GA3) }\end{array}$ & L-phenylalanine & $\begin{array}{l}\text { 2.8-fold } \\
\text { enhancement }\end{array}$ & $\begin{array}{l}\text { Skrzypczak- } \\
\text { Pietraszek } \\
\text { et al., } 2018\end{array}$ \\
\hline 35 & Anthocyanin & $\begin{array}{l}\text { Purple basil } \\
\text { (Ocimum basilicum } \\
\text { L. var. } \\
\text { purpurascens) }\end{array}$ & Callus cultures & $\begin{array}{l}\text { Temperature } \\
25 \pm 2^{\circ} \mathrm{C} ; \mathrm{pH} \\
5.6-5.7 ; 16 / 8 \mathrm{~h} \\
\text { light/dark }\end{array}$ & $\mathrm{NAA}(2.5 \mathrm{mg} / \mathrm{L})$ & $\begin{array}{l}\text { Melatonin and } \\
\text { UV-C radiations }\end{array}$ & $\begin{array}{l}\text { Melatonin } \\
\text { ( } 3.7 \text {-fold) and } \\
\text { UV-C radiations } \\
\text { ( } 4.1 \text {-fold) } \\
\text { increase }\end{array}$ & $\begin{array}{l}\text { Nazir et al., } \\
2020\end{array}$ \\
\hline 36 & Cynaroside & $\begin{array}{l}\text { Vitex agnus castus } \\
\text { L. }\end{array}$ & $\begin{array}{l}\text { Agitated shoot } \\
\text { cultures }\end{array}$ & $\begin{array}{l}\text { Rotary shaker at } \\
140 \mathrm{rpm}\end{array}$ & $\begin{array}{l}\alpha \text {-naphthaleneacetic } \\
\text { acid (NAA); } \\
\text { benzylaminopurine } \\
\text { (BAP); gibberellic } \\
\text { acid (GA3) }\end{array}$ & L-phenylalanine & $\begin{array}{l}1.5 \text {-fold yield } \\
\text { increase }\end{array}$ & $\begin{array}{l}\text { Skrzypczak- } \\
\text { Pietraszek } \\
\text { et al., } 2018\end{array}$ \\
\hline 37 & Luteolin & $\begin{array}{l}\text { Dracocephalum } \\
\text { kotschyi Boiss. }\end{array}$ & Seed germination & $\begin{array}{l}\text { Temperature } 28^{\circ} \mathrm{C} \\
\text { day } / 20^{\circ} \mathrm{C} \text { night; } \\
50 \% \text { air relative } \\
\text { humidity; } \\
\text { photoperiod of } 16 \mathrm{~h} \\
\text { light and } 8 \mathrm{~h} \text { dark }\end{array}$ & $\begin{array}{l}\text { Melatonin } \\
\text { (N-acetyl-5- } \\
\text { methoxytryptamine); } \\
\text { Calcium }\left(\mathrm{Ca}^{2+}\right)\end{array}$ & Salinity stress & $\begin{array}{l}\text { Salinity stress } \\
\text { alone } \\
\text { ( } 3.21 \text {-fold); } \\
\text { salinity stress } \\
\text { with melatonin } \\
\text { and } \mathrm{Ca}^{2+} \\
\text { (2.83-fold } \\
\text { increase) }\end{array}$ & $\begin{array}{l}\text { Vafadar et al., } \\
2020\end{array}$ \\
\hline 38 & Saikosaponins & $\begin{array}{l}\text { Bupleurum } \\
\text { falcatum } L \text {. }\end{array}$ & Root cultures & $\begin{array}{l}\text { Gyratory shaker } \\
105 \mathrm{rpm} ; \\
23 \pm 2^{\circ} \mathrm{C} ; 12: 12 \\
\text { light-dark cycle (h) }\end{array}$ & $\begin{array}{l}\text { Indole-3-butyric } \\
\text { acid (IBA) }\end{array}$ & $\begin{array}{l}\text { Two step } \\
\text { sucrose } \\
\text { concentration }\end{array}$ & $\begin{array}{l}\text { Four-fold yield } \\
\text { increase }\end{array}$ & $\begin{array}{l}\text { Kusakari et al., } \\
2000\end{array}$ \\
\hline 39 & $\begin{array}{l}\text { Phenolic } \\
\text { compounds }\end{array}$ & $\begin{array}{l}\text { Morinda coreia } \\
\text { Buck. And Ham. }\end{array}$ & $\begin{array}{l}\text { Adventitious roots } \\
\text { cultures }\end{array}$ & $\begin{array}{l}\text { Agitated in dark on } \\
\text { gyratory shaker at } \\
100 \text { rpm; } 25 \pm 2^{\circ} \mathrm{C} \\
\text { temperature for } \\
8 \text { days }\end{array}$ & $\begin{array}{l}\text { Indole-3-butyric } \\
\text { acid (IBA); BAP and } \\
\text { Kin }\end{array}$ & Chitosan & $\begin{array}{l}1.21 \text {-fold more } \\
\text { than IBA } \\
\text { treated root } \\
\text { suspension } \\
\text { culture }\end{array}$ & $\begin{array}{l}\text { Kannan et al., } \\
2020\end{array}$ \\
\hline 40 & $\begin{array}{l}\text { Essential oils } \\
\text { (Thymol and } \\
\text { p-cymene) }\end{array}$ & Carum copticum L. & Callus cultures & $\begin{array}{l}\text { Temperature } 25^{\circ} \mathrm{C} \text {; } \\
\text { pH 5.8; } 16-\mathrm{h} \\
\text { photoperiod } \\
\text { supplied by white } \\
\text { fluorescent lamps } \\
\text { at } 90 \mathrm{Imol} \mathrm{m}^{-2} \mathrm{~s}^{-1} \\
\text { in growth chamber }\end{array}$ & $\begin{array}{l}\text { 2,4- } \\
\text { dichlorophenoxyacetic } \\
\text { acid (2,4-D); benzyl } \\
\text { amino purine (BAP) }\end{array}$ & $\begin{array}{l}\text { Salt stress and } \\
\text { chitosan }\end{array}$ & $\begin{array}{l}\text { Thymol (from } \\
14.5 \text { to } \\
25.1 \text {-fold); } \\
\text { p-cymene (from } \\
10 \text { to } 14.5 \text {-fold } \\
\text { increase) }\end{array}$ & $\begin{array}{l}\text { Razavizadeh } \\
\text { et al., } 2020\end{array}$ \\
\hline
\end{tabular}

CdCl, cadmium chloride; MSRs, Murashige and skoog-Rhodiola rosea medium; IBA, indole-3-butyric acid; NAA, naphthaleneacetic acid; MeJa, methyl jasmonate; SA, salicylic acid; 2, 4D, 2,4-dichlorophenoxyacetic acid; Kn, kinetin; BAP, 6-Benzylaminopurine; PEG, polyethylene glycol; GA, gibberellic acid; TDZ, thidiazuron; BA, 6-benzyaldenine. 


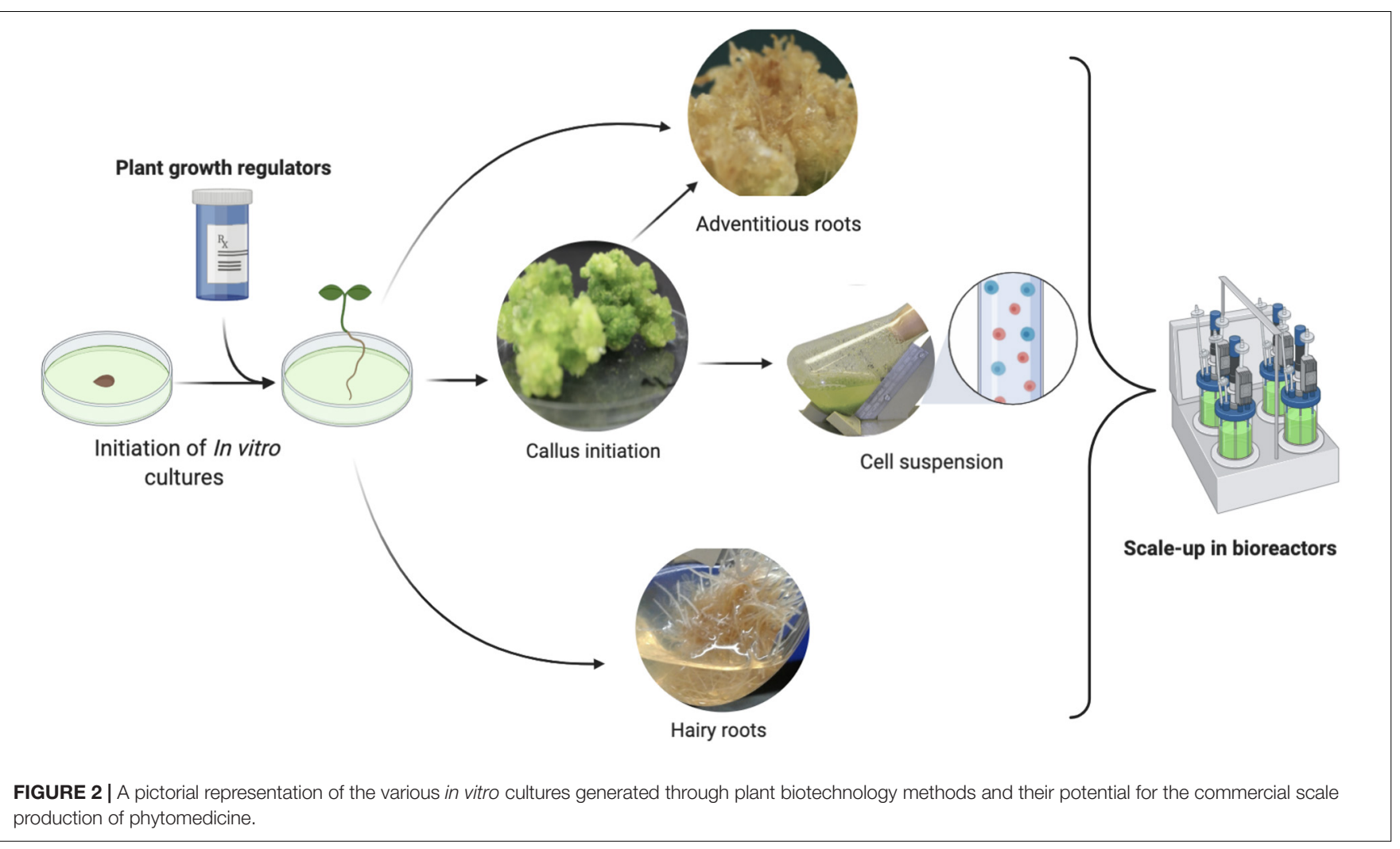

secretory organs (Khan et al., 2019a). Similarly, results from another study have shown that callus cultures of Carum copticum also accumulated higher levels of thymol and p-cymene than their wild-grown respective plants (Razavizadeh et al., 2020).

Light intensity or quality during in vitro cultures can influence the plant cell's physiological and hormonal status through the initiation of distinct metabolic pathways that ultimately influence and regulate the biosynthesis of important essential oils (Giri and Zaheer, 2016; Ali et al., 2018b). In cell cultures of Ocimum basilicum, constant light illumination produced higher total essential oil yield including the potent volatile linalool than the cell cultures grown under complete darkness. The process of elicitation by application of chemical elicitors, e.g., phenylacetic acid and methyl jasmonate and under the effects of physical elicitors such as the absence of light illuminance in the cultures have positively influenced the production of medicinally potent metabolites in an A. bracteosa cell culture (Ali et al., 2018b). In another study, important monoterpenes such as limonene and terpinolene (potential anti-SARS-CoV-2 metabolites) were elicited by methyl jasmonate under dark in higher amounts in Rosa damascene cell cultures (Olgunsoy et al., 2017). The process of elicitation is directly linked with the biosynthesis of essential oils in the plant cell. Several factors are responsible for the regulation of volatile compound biosynthesis. These factors include the genetic makeup of the explant used in cell cultures, the type of culture media, and the in vitro developmental phase of plant cells (Holopainen, 2011). There are, however, many limitations to cell suspension culture technology including slow growth and scale-up hurdles, the instability of cell lines, and subsequent lower yield of some important metabolites (Abbasi et al., 2016). Nevertheless, optimization of cell cultures could result in the generation of very viable factories to produce medicinal compounds that could work against SARS-CoV-2 and other human viruses.

\section{Hairy Roots}

Generally, the potential of plant cell cultures to produce bioactive secondary metabolites can be enhanced by the induction of cell differentiation. Within the different cell culture approaches, hairy root cultures hold tremendous potential for the biosynthesis of volatile organic compounds besides other classes of potent secondary metabolites. When plant tissue is genetically transformed by Agrobacterium rhizogenes which inserts its T-DNA through the Ri plasmid, it results in the formation of hair-like small and fine roots. The advantage of hairy root culture technology is that it does not require further media supplementation with plant growth regulators because the inserted T-DNA carries the genes responsible for the endogenous biosynthesis of auxins. Lacking the property of geotropism, hairy roots are highly branched and can grow faster than normal roots. They not only produce the metabolites at levels like the normal roots but also generate metabolites that are produced in the aerial parts of the natural plants. Furthermore, hairy roots are physiologically and biochemically stable like any other cell culture technology (Gounaris, 2010). An excellent study has concluded the potential of hairy roots culture technology for the optimal production of antiviral flavonoids in Isatis tinctoria (Jiao et al., 2018). Isatis tinctoria (A.K.A. Isatis indigotica) has 
been shown to possess potential against SARS-CoV through its root-derived phytochemicals (Li et al., 2005). Among the different plants, the hairy roots of Pimpinella anisum and Achillea millefolium resulted in the production of medicinally important essential oils (Santos et al., 1998). In certain cases, such as the hairy roots of Daucus carota and Laburnum alpinum, the essential oil profiles of the volatiles were found in elevated levels, compared with the respective callus and cell cultures. Further, the metabolic pathways for the biosynthesis of volatiles can be manipulated by using more effective transgenes that can be inserted into the T-DNA region.

\section{ELICITATION OF IN VITRO CULTURES; A PROMISING AVENUE FOR ANTI-CORONAVIRUS MEDICINAL COMPOUNDS}

Apart from the diversity of in vitro cultures, which can provide avenues for phytochemical compounds against SARS$\mathrm{CoV}-2$, enhanced production of these compounds is one area where plant biotechnology thrives. This enhancement is achieved through triggering or in other words eliciting the defense response of plant cultures, discussed in the previous section. To give a very brief overview of the mechanism of elicitation, the process starts at the cell membrane of the plant cell. Many different receptors are elicited to trigger the secondary metabolism for defense. For instance, the plasmalemma membrane-associated receptors attach the ligand or chemical compound (exogenous or endogenous). The signal reception is followed by transduction which includes steps like reversible phosphorylation and dephosphorylation of plasma membrane and cytosolic proteins, enhancement of $\mathrm{Ca}^{2+}$ in the cytosol, $\mathrm{H}^{+}$influx $/ \mathrm{Cl}^{-}$and $\mathrm{K}^{+}$efflux, extracellular alkalinization and cytoplasmic acidification, mitogen-activated protein kinase (MAPK) activation, NADPH oxidase activation and production of reactive oxygen and nitrogen species (ROS and RNS), early defense gene expression, jasmonate production, late defense response gene expression, and secondary metabolite accumulation (Ramirez-Estrada et al., 2016).

Being of biological origin (biotic) or non-biological origin (abiotic), the compounds or physical factors that stimulate the plant defense are termed elicitors. Biotic elicitors include compounds that are of the pathogenic origin or are produced by the plants after being exposed to pathogens. Abiotic elicitors include chemical compounds such as salts or physical factors such as environmental triggers (Devaux et al., 2020). The most relevant example of elicitation of important anti-SARS-CoV metabolites is that of glycyrrhizin from Glycyrrhiza glabra L. G. glabra L. has become an endangered medicinal plant due to the unabated extraction of glycyrrhizin (Srivastava et al., 2019). Glycyrrhizin is a triterpenoid saponin and has been shown to possess strong antiviral activity in killing SARS-CoV in a lancet study (Cinatl et al., 2003). Srivastava et al. (2019) have successfully elicited the yield of glycyrrhizin in hairy root cultures of G. glabra L. Through this study, it was proven that both biotic and abiotic elicitors are effective in eliciting higher yields of glycyrrhizin.

\section{Biotic Elicitors Can Trigger the Production of Plant Secondary Metabolites Against SARS-CoV-2}

Compounds of a biological origin that elicit plant defense response and thus produce higher quantities of secondary metabolites are produced in two ways. Biotic elicitors are either compounds coming from pathogens, i.e., exogenous in origin or are compounds/hormones produced as a response to the pathogen that in turn triggers the plant's defense response (endogenous elicitors). Plant in vitro cultures have been used as factories for the enhanced production of medicinally secondary metabolites through the application of many different exogenous and endogenous elicitors (Srivastava et al., 2019). Exogenous biotic elicitors include bacterial lysates, microbial enzymes, polysaccharides (chitin), and yeast extracts. For instance, cellulase, which directly serves bacteria and fungi and helps in attacking plant cell walls, has been shown to enhance the production of glycyrrhizin up to 8.6-fold through the application of cellulase to the hairy roots of G. glabra L. Besides, mannan oligosaccharides derived from the cell wall of yeasts (Saccharomyces cerevisiae) (De Oliveira et al., 2014) have also been reported to trigger the enhanced production of glycyrrhizin (7.8-fold compared to control) in hairy root cultures of G. glabra L. It should be reiterated here that glycyrrhizin possesses a demonstrated activity against the previously epidemic SARS-CoV. This saponin from licorice roots can inhibit the replication of SARS-associated coronavirus with an $\mathrm{EC}_{50}$ value ranging from 300 to $600 \mathrm{mg} / \mathrm{L}$ (Cinatl et al., 2003). Similarly, methyl jasmonate, a very important endogenous biotic elicitor has been shown to be effective in enhancing the production of glycyrrhizin up to almost 109 micrograms/g dry weight after 5 days of elicitation with $100 \mathrm{mM}$ of methyl jasmonate. The study also demonstrated the role of other elicitors such as chitosan and yeast extract on the production of glycyrrhizin and demonstrated their effectiveness (Wongwicha et al., 2011). Other biotic elicitors ascorbic acid, eugenol, salicylic acid, and yeast extract have been employed for the enhancement of glycyrrhizin in cell cultures of Abrus precatorius (Karwasara et al., 2010).

Similarly, a higher yield of trans-resveratrol, previously shown to act strongly against MERS-CoV, has been reported in cell suspension cultures of Vitis vinifera through the application of 2, 3-dihydroxypropyl jasmonate (Shen et al., 2012). Chitosan is a polysaccharide that acts as a biotic elicitor and is used for highyield production of medicinally important secondary metabolites (Hadwiger, 2013). Results from the study of Ferri et al. (2009) revealed that chitosan enhanced the production of important polyphenols, including stilbenes and flavonoids in cell cultures of $V$. vinifera. There are innumerable studies available on enhancing the yields of many important plant secondary metabolites that could be very effective in dealing with SARS-CoV-2. Plant secondary metabolites such as lycorine, reserpine, plant lectins, apigenin, luteolin, and quercetin (replication inhibitors of coronavirus) (Wu et al., 2004; Li et al., 2005; Keyaerts et al., 2007; 
Ryu et al., 2010a) have been elicited through the use of biotic elicitors including methyl jasmonate, salicylic acid, and chitosan (Dyakov et al., 2007; Ptak et al., 2017; Chandran et al., 2020).

\section{Enhanced Production of Anti-coronavirus Plant Secondary Metabolites Through Abiotic Elicitors}

Just like biotic elicitors, chemical compounds of abiotic origin and physical factors such as environmental stimuli have also been proven effective in the elicitation of plant defense and thus increased production of phytochemicals (Halder et al., 2019). It is not possible to cover all abiotic elicitors in a single subsection, but for our purpose, abiotic elicitors compounds such as salts (e.g., $\mathrm{AgNO}_{3}, \mathrm{CdCl}_{2}$, etc.) and environmental stimuli such as continuous light/dark, different wavelengths of light, and osmotic stress, etc. have been employed to produce high-yield secondary metabolites in plant in vitro cultures.

Abiotic elicitation has been used for the enhanced production of important flavonoids such as hypericin and hyperforin in in vitro cultures of Hypericum perforatum (Shakya et al., 2019). For instance, Tirillini et al. (2006) reported that the application of chromium $(0.01 \mathrm{mM})$ increased the production of hypericin by $38 \%$ in plantlets of $H$. perforatum (Tirillini et al., 2006). Compounds such as quercetin in $H$. perforatum have been shown to act as potent anti-SARS-CoV compounds and their enhanced production through elicitation promises an avenue for high-yield drug production (Ryu et al., 2010a; Shakya et al., 2019). A new addition to the lines of abiotic elicitors is the use of nanomaterials for triggering an intense plant defense response. For example, in one of our studies, we used silver nanoparticles (AgNPs) for the enhancement of medicinally important phenolics and flavonoids in callus cultures (Begum et al., 2020). Similarly, zinc nano-oxides and iron nano-oxides have been used to trigger the production of hypericin and hyperforin in cell suspension cultures of $H$. perforatum (Shakya et al., 2019). Apart from chemical compounds, environmental triggers have also proved to be valuable tools in plant biotechnology for the enhanced production of important secondary metabolites in plant in vitro cultures. For example, Khan et al. (2019c) showed that different spectral lights result in the enhanced production of phytochemicals such as myricetin and apigenin among many others. Myricetin is experimentally shown to inhibit the SARS$\mathrm{CoV}$ helicase protein in vitro by affecting ATPase activity and thus could have potential against SARS-CoV-2 (Yu et al., 2012). Plants in vitro cultures can serve as factories for the elicitorinduced high-yield production of myricetin against SARS-CoV-2. In another study, Huang et al. (2016) used UV-B irradiation to cause flavonoid-related gene expression in hairy root cultures of Fagopyrum tataricum. The experiment resulted in enhanced biosynthesis of rutin and quercetin in the hairy root cultures of F. tataricum.

Conclusively, the application of biotic and abiotic elicitors during plant in vitro cultures is a promising avenue for the production of enhanced quantities of drug candidates against SARS-CoV-2.

\section{GENETIC ENGINEERING OF PLANTS FOR ENHANCED METABOLITES BIOSYNTHESIS}

Few reports are available on the genetic engineering of different plant species through a transformation with the candidate genes responsible for medicinal metabolites biosynthesis. Particularly, the metabolic pathways responsible for producing antiviral metabolites. In these studies, the cauliflower mosaic virus promoter (CaMV 35S) was used for the overexpression of the reductoisomerase DXR of the mevalonate MEP pathway in peppermint, and a significantly higher (50\%) increase in total essential oil production was observed. The yields of cyclic monoterpenes were enhanced by the overexpression of the limonene synthase enzyme in the plastid. The overexpression of the rate-limiting factors significantly enhanced the specific yield of monoterpenes (Daviet and Schalk, 2010). It is crucial in some instances to enhance the yield of specific compounds of interest such as the monoterpenes $\alpha$-pinene and d-limonene which are suitable alternatives to hazardous chemicals. Thus, the in vitro cultures through a genetic transformation in plants can boost the production of the desired compounds (Roberts, 2007). For instance, the production of monoterpene alcohols can be accelerated by the overexpression of linalool synthase, the enzyme responsible for the profound production of glycosylated forms than the free form. Likewise, overexpression of prenyltransferase has been found to increase the yields of the linear as well as some cyclic sesquiterpenes (Gounaris, 2010).

\section{METABOLIC ENGINEERING OF PLANTS FOR PRODUCTION AND ENHANCEMENT OF ANTI-CORONAVIRUS COMPOUNDS}

The metabolic machinery of plants could be targeted for engineering at different points that ultimately result in either novel compounds or the over-production of important medicinal metabolites (Figure 3). The metabolic engineering of plants is one area of plant biotechnology that possesses enormous potential for producing anti-SARS-CoV-2 compounds. Many of such pharmacological compounds have been extensively studied and reported in the literature (De Luca et al., 2012; Atanasov et al., 2015; Wurtzel and Kutchan, 2016; Buyel, 2018). Traditionally, people take these compounds orally as a whole plant, its decoction, or as a crude extract. However, it can be detrimental as most of the time unwanted compounds are also administered. Besides, these compounds are present at low native concentrations in plants and most of the time is not as effective as a pure compound. Commercial extraction of any such compound from any plant species may have detrimental effects on the plant population and can even push a plant species to the brink of extinction (Barone et al., 2019). For example, mass production of paclitaxel (source of $\operatorname{Taxol}^{\circledR}$ ) led to the endangerment of not only its source plant (Pacific yew) but also other species of the same genus (Hawkins, 2007). 


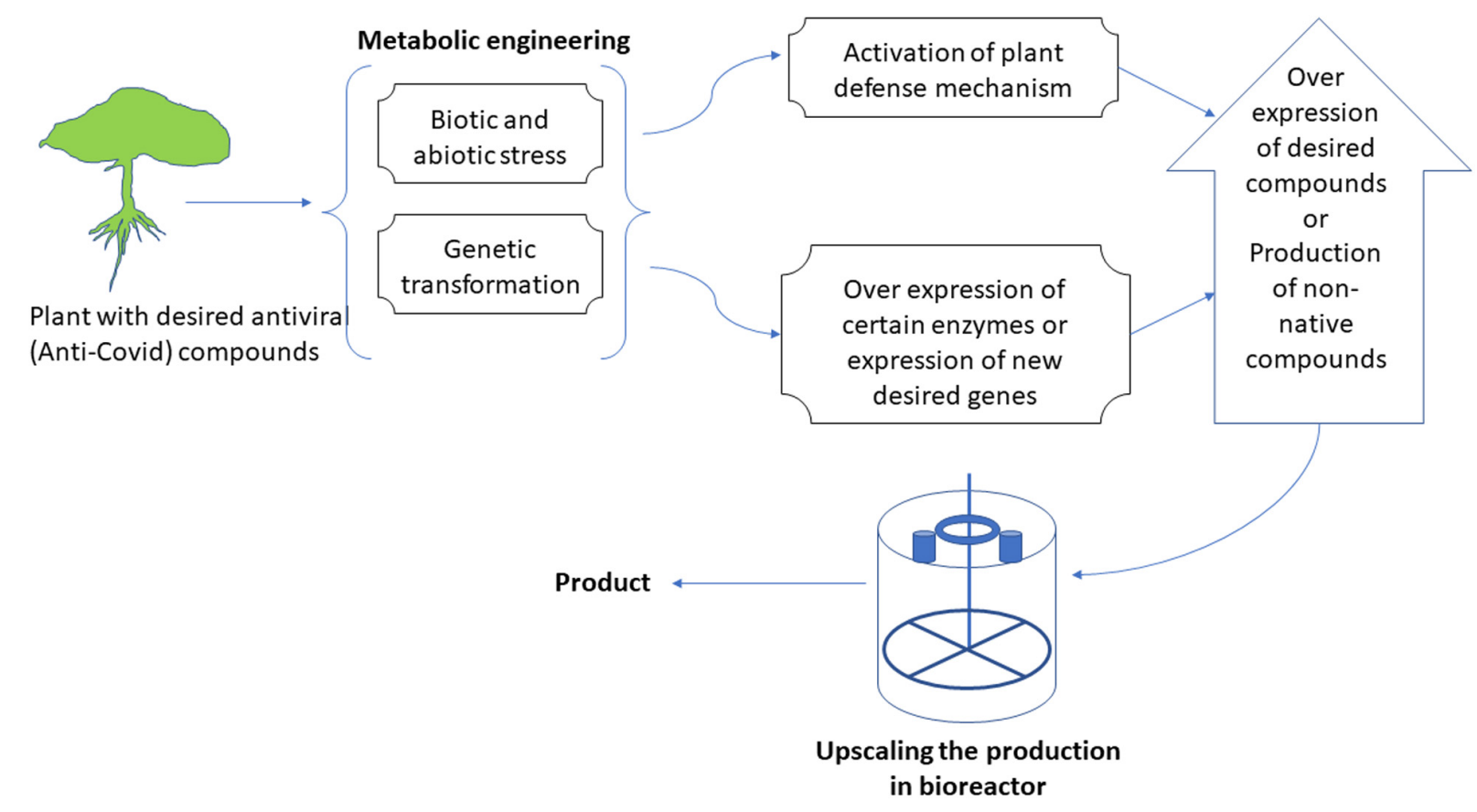

FIGURE 3 | A representative flow-chart for the process of metabolic engineering of in vitro cultures to produce novel compounds or to over-produce existing compounds.

Thus, an increasing interest has been observed focusing on in-planta production of important metabolites via genetic and metabolic engineering. For example, genistein and taxane (precursors of paclitaxel) have been successfully produced in plants other than their native species. However, alongside attempting the increased production of certain end-products or producing new products/compounds via genetic engineering, it has been understood that biosynthetic engineering is a highly complicated process that demands diverse knowledge in all fields of biochemistry, biotechnology, and molecular biology (Barone et al., 2019). Several in vitro cultures for growing plant tissues could be manipulated through metabolic engineering for secondary metabolite production and its quantity enhancement, for example; adventitious root culture, callus culture, somatic embryogenesis and regeneration, cell suspension culture, protoplast culture, and hairy root culture, etc. (Gantait et al., 2020).

Despite drawbacks, attempts to overproduce a single metabolite or end-product have progressed in recent years and several examples can be found in the literature in which metabolic engineering of plants has been applied in the field of medicine. For instance, the production of genistein, an isoflavone, and a known antiviral compound has been shown in non-leguminous species in which this compound is not native. It was made possible by introducing the isoflavone synthase (IFS) gene from soybean (glycine max) to non-leguminous species tobacco (Nicotiana tabacum), lettuce (Lactuca sativa), and petunia (Petunia hybrida) (Barone et al., 2019). Furthermore, to increase the quantity of genistein, anti-sense suppression of flavanone-3-hydroxylase ( $\mathrm{F} 3 \mathrm{H})$ and overexpression of phenylalanine ammonia-lyase (PAL) has also been employed. It is important to highlight here that PAL is an enzyme of the phenylpropanoid pathway that feeds into flavonoid biosynthesis.

Artemisinin commercially known for its antimalarial activity is also reported for its antiviral activity (Lubbe et al., 2012). The low concentration of artemisinin in its native plant the sweet wormwood (Artemisia annua) and its high demand in the pharmaceutical industry have led researchers to investigate its in-planta production as well as in other culture systems. Although little success has been made in this direction, a potential bottleneck has been identified which may lead to its biosynthesis in the near future.

In another study, sweet wormwood has been successfully transformed using Agrobacterium tumefaciens to produce taxane (a paclitaxel precursor) (Li et al., 2015). It should be noted that paclitaxel is a famous anticancer compound and is also known for its anti-HIV activity (Ryang et al., 2019).

Glycyrrhizin, an active component of licorice roots, has been reported to show antiviral activity against SARS-CoV in vitro (Boccalone et al., 2020). This compound has been converted via biotransformation to several other compounds that are more stable, easily soluble, and having greater emulsifying properties than glycyrrhizin. Other advantages of biotransformation of glycyrrhizin include strong stereoselectivity and regioselectivity, low byproduct production, and increased activity (He et al., 2019). It has been found that cell suspension culture of G. glabra and Eucalyptus perriniana can transform glycyrrhetinic acid (a byproduct of glycyrrhizin) to several other important compounds. For instance, these include $3-O-[\alpha-1-$ arabinopyranosyl $-(1 \rightarrow 2)-\beta-\mathrm{D}-$ glucuronopyran 
osyl]-24-hydroxy-18 $\quad \beta$-glycyrrhetinic acid, 23,28 -dihydroxy-18 $\beta$-glycyrrhetinic acid-30 $\beta$-glucopy ranosyl ester, and 28-hydroxy-18 $\beta$-glycyrrhetinic acid-30 $\beta$-glucopyranosyl ester which are reported to be important medicinal compounds (Hayashi et al., 1990; Orihara and Furuya, 1990).

Resveratrol is another example of a natural product that is reported for its anti-coronavirus activity (Lin et al., 2017) and has been successfully transformed via molecular engineering into plants that normally do not produce resveratrol (Giovinazzo et al., 2012). This compound has been reported to be found in grapes, berries, white tea, and passion fruit, etc. in a very low quantity which makes its extraction challenging (Shrestha et al., 2019). Metabolic engineering has been performed by several researchers to improve its quantity or to express it in new plants (Giovinazzo et al., 2012). For instance, the expression of grape genetic markers in tobacco leaves diverted the typical substrates of chalcone synthase to produce CHS up to $300 \mathrm{mg} / \mathrm{g}$ of resveratrol (Halls and $\mathrm{Yu}, 2008$ ).

Plant metabolic engineering could prove to be an important tool in directing a plant's metabolic machinery to the synthesis of important natural compounds against coronaviruses. For instance, metabolically engineered soybean and canola produced a high level of monosaturated fatty acid which otherwise produces a high level of linolenic acid which is prone to oxidation (Dellapenna, 2001). In another example, the use of g-tocopherol methyltransferase (g-TMT) showed a 10-fold increase in vitamin E activity in engineered Arabidopsis seed oil (Shintani and Dellapenna, 1998). In an example of metabolic engineering, b-carotene (provitamin A) has been successfully engineered into rice endosperm (Ye et al., 2000). 3-O-glucosyl-resveratrol production in a $V$. vinifera cell culture was significantly stimulated by saliva, with a 7.0 -fold increase compared to control (Cai et al., 2012). Methyl jasmonate elicitation is an effective strategy to induce and enhance the synthesis of the anticancer agent paclitaxel $\left(\mathrm{Taxol}^{\circledR}\right)$ in taxus cell suspension cultures (Patil et al., 2014).

In an interesting experiment, $N$. tabacum plants were transformed with the stilbene synthase gene from grapevine using A. tumefaciens-mediated gene transfer. The transformed plants not only expressed the gene but also showed resistance to the fungal pathogen Botrytis cinerea (Hain et al., 1993). Metabolic engineering has thus improved its composition as well as improved its level. Stilbene synthase gene (STS-encoding gene)mediated transformation thus confirmed that plant molecular engineering with resveratrol may lead to novel functions such as resistance to stresses, fungal infection, or increased nutritional value. STS genes have been transferred to several other crops as well such as Medicago sativa L., Arabidopsis thaliana L, L. sativa $L$, and Solanum lycopersicum L., etc. (Giovinazzo et al., 2012). The gene expression is however controlled by the chosen promoter. Commonly used promoters to control the expression of STS-encoding genes include the well-characterized constitutive promoter pCaMV35S, fungus-inducible promoter pPR10.1, stress-responsive promoter pVst1, and the tissuespecific promoter p-nap (Stark-Lorenzen et al., 1997; CoutosThévenot et al., 2001; Fan et al., 2008). The increased nutritional values of several fruits and edible crops via transformation along with the higher yield of resveratrol can be exploited for use in SARS-CoV-2 management.

Ginsenoside (ginsenoside Rb1) occupies a unique place in the pharmaceutical industry around the globe as an active ingredient of Panax ginseng. It has recently been reported for its anti-SARS-CoV activity (Boccalone et al., 2020). While the traditional methods of isolation and purification of ginsenoside were challenging and time-consuming, the use of modern-day biotechnological approaches not only enhances its level but also makes the extraction process easier. These approaches include but are not limited to tissue culture, cell suspension culture, protoplast culture, polyploidy, in vitro mutagenesis, and hairy root culture (Gantait et al., 2020). For instance, Yu et al. (2016) have reported the enhanced production of ginsenoside by using a fungal strain Alternaria panax in cell suspension cultures. The cell wall exudates fungi that contain oligosaccharides and chitin that act as biotic elicitors (Yu et al., 2016).

Jasmonates have been reported to induce oxidative stress and downregulate many genes which lead to an augmentation of ginsenoside in the cell suspension culture. The mechanism behind the role of the elicitor mainly involve the activation of phenylalanine amino lyase which in turn elevates the level of defense compounds and hence ginsenoside biosynthesis ( $\mathrm{Yu}$ et al., 2002; Kim et al., 2004; Wang et al., 2006).

Mutagenesis and in vitro cultures which incorporate genotypic changes in the culture is another popular method used for the enhanced production of ginsenoside. In this method, P. ginseng calli are exposed to varying doses of gamma radiation ranging from 10 to 100 Gy (Gray) and for various lengths of time to bring genetic changes and hence to increase the ginsenoside level in callus cultures (Kim et al., 2009, 2013). The increased production of primary ginsenosides was associated with the high expression of squalene epoxidase, dammarenediol synthase, and phytosterol synthase genes (Kim et al., 2013). Summing up, it can be concluded that engineering plant cell and tissue cultures, through in vitro mutagenesis, direct gene transfer, and A. tumefaciens-mediated transformation could play an important role in the production/enrichment of natural products that are easily repeatable in a short time and thus can be exploited in the fight against COVID-19.

\section{COMMERCIALIZATION OF PLANT IN VITRO CULTURES FOR SECONDARY METABOLITE PRODUCTION}

Advances in biotechnological approaches, particularly plant cell culturing methods, provides new means for commercially valuable, medicinally important plant secondary metabolites (Hussain et al., 2012). Different kinds of strategies have been used, for example, appropriate design of bioreactor systems, optimization of nutrient medium, highly productive line selection, elicitation, two-phase cultivation, and metabolic engineering (Marchev et al., 2020). The scaling-up of in vitro 
plant culturing into large-scale, economically feasible bioreactors provides the sustainable and continuous production of highvalued plant secondary metabolites. Secondary metabolite production in bioreactors depends on pharmacological significance as well as human health benefits. The production of rosmarinic acid and saponins are the selected examples of the commercial production of secondary metabolites in vitro (Weathers et al., 2010). Different kinds of bioreactor systems are used to enhance the accumulation of rosmarinic acid such as hairy root cultures or shoot suspension cultures from different plants. Plant suspension culture technology offers a convenient way of upscaling plant in-vitro culture systems for the biosynthesis of secondary metabolites. The ease of its upscale is attributed to its shorter cycle of production and simpler methods for bioreactor construction (Marchev et al., 2020). The successful and rapid development of plant metabolic engineering offers an attractive opportunity to increase the content of secondary metabolites in cell and hairy root cultures from aromatic and medicinal plants at a feasible level. Moreover, plant metabolic engineering also makes it possible to understand the molecular biology of the biosynthesis of the secondary metabolites (Pavlov and Bley, 2018). Ginsenoside and taxole, examples of successfully commercialized plant cell suspension cultures, derived specialized metabolites. As reported earlier (Table 1), ginsenosides have proven to be effective against SARS-CoV in inhibiting glycoprotein activity (Wu et al., 2004). Although due to the limited understanding of the molecular basis of plant secondary metabolite biosynthesis, the widespread utilization of the plant suspension cultures platform has yet to be primarily realized (Arya et al., 2020). However, with much research effort, many secondary metabolites achieved a semi-commercial status (Weathers et al., 2010).

Regarding commercialization, the most promising fact associated with plant tissue cultures is that they offer an avenue for the production of these medicinally important phytochemicals in an appropriate bioreactor. The production of the plant in vitro cultures is indeed an important prerequisite for the large-scale yield and commercialization of phytomedicine. This is linked with the fact that once carefully selected and optimized, in vitro cultures of plants could yield ten times higher phytomedicine than plants grown naturally. However, the production of phytomedicine in bioreactors requires the selection of suitable cell lines/cultures, optimization of culture conditions, application of proper elicitation strategy, immobilization of cells, and efficient downstream processing (Marchev et al., 2020).

\section{REFERENCES}

Abbasi, B. H., Ali, H., Yücesan, B., Saeed, S., Rehman, K., and Khan, M. A. (2016). Evaluation of biochemical markers during somatic embryogenesis in Silybum marianum L. 3 Biotech 6:71. doi: 10.1007/s13205-0160366-1

Abraham, J. (2020). Passive antibody therapy in COVID-19. Nat. Rev. Immunol. 20, 401-403. doi: 10.1038/s41577-020-0365-7

Abyari, M., Nasr, N., Soorni, J., and Sadhu, D. (2016). Enhanced accumulation of scopoletin in cell suspension culture of Spilanthes acmella Murr. using precursor feeding. Braz. Arch. Biol. Technol. 59:e16150533. doi: 10.1590/16784324-2016150533
Commercial production of secondary metabolites largely depends either on higher market value or high demand which will undoubtedly be high if any of the phytochemicals tested proved effective against the current SARS-CoV virus. The continuous efforts in this field will lead to the controllable and successful production of specific, valuable, and yet unknown plant secondary metabolites (Hussain et al., 2012) against human viruses specifically coronaviruses. Such understanding will ultimately lead to the production of important phytochemicals that are active against SARS-CoV-2.

\section{CONCLUSION}

Plant biotechnology is a promising platform for exploring the unlimited potential of many diverse medicinal plants. Unfortunately, pandemics like COVID-19 are likely to occur again on a smaller or larger scale due to the array of known and unknown pathogens out there. Plant biotechnology tools and methods such as in vitro culture technology is an asset at our disposal to harness the diversity of secondary metabolites produced by different plants. In vitro culture technologies can potentially grow any plant anywhere and offer the added value of overproduction of plant cultures, enhanced production of secondary metabolites, and the generation of novel medicinal compounds.

\section{AUTHOR CONTRIBUTIONS}

TK and MK conceived the idea. TK, KK, MK, NU, and AN each drafted a different section of the manuscript. MK critically reviewed the manuscript. KK and Z-U-RM gathered the data and prepared and formatted the tables. TK, KK, and MK performed the revisions. TK constructed the figures and formatted the manuscript. All authors contributed to the article and approved the submitted version.

\section{ACKNOWLEDGMENTS}

The authors acknowledge their respective institutions for providing the opportunity to collaborate with their colleagues in other institutions.

Ali, H., Khan, M. A., Kayani, W. K., Khan, T., and Khan, R. S. (2018a). Thidiazuron regulated growth, secondary metabolism and essential oil profiles in shoot cultures of Ajuga bracteosa. Ind. Crops Prod. 121, 418-427. doi: 10.1016/j. indcrop.2018.05.043

Ali, H., Khan, M. A., Ullah, N., and Khan, R. S. (2018b). Impacts of hormonal elicitors and photoperiod regimes on elicitation of bioactive secondary volatiles in cell cultures of Ajuga bracteosa. J. Photochem. Photobiol. B Biol. 183, 242-250. doi: 10.1016/j.jphotobiol.2018.04.044

Arya, S. S., Rookes, J., Cahill, D., and Lenka, S. K. (2020). Next-generation metabolic engineering approaches towards development of plant cell suspension cultures as specialized metabolite producing biofactories. Biotechnol. Adv. 45:107635. doi: 10.1016/j.biotechadv.2020.107635 
Atanasov, A. G., Waltenberger, B., Pferschy-Wenzig, E.-M., Linder, T., Wawrosch, C., Uhrin, P., et al. (2015). Discovery and resupply of pharmacologically active plant-derived natural products: A review. Biotechnol. Adv. 33, 1582-1614. doi: 10.1016/j.biotechadv.2015.08.001

Awad, V., Kuvalekar, A., and Harsulkar, A. (2014). Microbial elicitation in root cultures of Taverniera cuneifolia (Roth) Arn. for elevated glycyrrhizic acid production. Ind. Crops Prod. 54, 13-16. doi: 10.1016/j.indcrop.2013.12.036

Bannerman, R. H. O., Burton, J., Bannerman, R. H., Ch'en, W. C., and World Health, O. (1983). Traditional Medicine and Health Care Coverage: A Reader for Health Administrators and Practitioners. Geneva: World Health Organization.

Barone, R. P., Knittel, D. K., Ooka, J. K., Porter, L. N., Smith, N. T., and Owens, D. K. (2019). The production of plant natural products beneficial to humanity by metabolic engineering. Curr. Plant Biol. 24:100121. doi: 10.1016/j.cpb.2019. 100121

Bassolino, L., Giacomelli, E., Giovanelli, S., Pistelli, L., Cassetti, A., Damonte, G., et al. (2015). Tissue culture and aromatic profile in Salvia dolomitica Codd. Plant Cell Tissue Organ Cult. 121, 83-95. doi: 10.1007/s11240-014-0681-3

Begum, S., Zahid, A., Khan, T., Khan, N. Z., and Ali, W. (2020). Comparative analysis of the effects of chemically and biologically synthesized silver nanoparticles on biomass accumulation and secondary metabolism in callus cultures of Fagonia indica. Physiol. Mol. Biol. Plants 26, 1739-1750. doi: 10. 1007/s12298-020-00851-w

Ben-Shabat, S., Yarmolinsky, L., Porat, D., and Dahan, A. (2020). Antiviral effect of phytochemicals from medicinal plants: applications and drug delivery strategies. Drug Deliv. Transl. Res. 10, 354-367. doi: 10.1007/s13346-01900691-6

Boccalone, E., Lanni, V. M., and Magro, V. M. (2020). Role of natural drugs in severe acute respiratory syndrome coronavirus 2: potential beneficial effects in prevention or prior treatment in elderly and cancer patients. Geriatr. Care 6:9016. doi: $10.4081 /$ gc. 2020.9016

Buyel, J. (2018). Plants as sources of natural and recombinant anti-cancer agents. Biotechnol. Adv. 36, 506-520. doi: 10.1016/j.biotechadv.2018.02.002

Cai, Z., Knorr, D., and Smetanska, I. (2012). Enhanced anthocyanins and resveratrol production in Vitis vinifera cell suspension culture by indanoylisoleucine, N-linolenoyl-l-glutamine and insect saliva. Enzyme Microb. Technol. 50, 29-34. doi: 10.1016/j.enzmictec.2011.09.001

Callaway, E. (2020). The race for coronavirus vaccines: a graphical guide. Nature 580, 576-577. doi: 10.1038/d41586-020-01221-y

Capell, T., Twyman, R. M., Armario-Najera, V., Ma, J. K. C., Schillberg, S., and Christou, P. (2020). Potential applications of plant biotechnology against SARS-CoV-2. Trends Plant Sci. 25, 635-643. doi: 10.1016/j.tplants.2020.04.009

Chandran, H., Meena, M., Barupal, T., and Sharma, K. (2020). Plant tissue culture as a perpetual source for production of industrially important bioactive compounds. Biotechnol. Rep. 26:e00450. doi: 10.1016/j.btre.2020.e00450

Chen, L., Li, J., Luo, C., Liu, H., Xu, W., Chen, G., et al. (2006). Binding interaction of quercetin-3- $\beta$-galactoside and its synthetic derivatives with SARS-CoV 3CLpro: Structure-activity relationship studies reveal salient pharmacophore features. Bioorg. Med. Chem. 14, 8295-8306. doi: 10.1016/j.bmc.2006.09.014

Cheng, P. W., Ng, L. T., Chiang, L. C., and Lin, C. C. (2006). Antiviral effects of saikosaponins on human coronavirus $229 \mathrm{E}$ in vitro. Clin. Exp. Pharmacol. Physiol. 33, 612-616. doi: 10.1111/j.1440-1681.2006.04415.x

Cinatl, J., Morgenstern, B., Bauer, G., Chandra, P., Rabenau, H., and Doerr, H. W. (2003). Glycyrrhizin, an active component of liquorice roots, and replication of SARS-associated coronavirus. Lancet 361, 2045-2046. doi: 10.1016/S01406736(03)13615-X

Coutos-Thévenot, P., Poinssot, B., Bonomelli, A., Yean, H., Breda, C., Buffard, D., et al. (2001). In vitro tolerance to Botrytis cinerea of grapevine $41 \mathrm{~B}$ rootstock in transgenic plants expressing the stilbene synthase Vst 1 gene under the control of a pathogen-inducible PR 10 promoter. J. Exp. Bot. 52, 901-910. doi: 10.1093/jexbot/52.358.901

Darvishi, E., Kahrizi, D., Bahraminejad, S., and Mansouri, M. (2016). In vitro induction of $\alpha$-pinene, pulegone, menthol, menthone and limonene in cell suspension culture of pennyroyal (Mentha pulegium). Cell. Mol. Biol. 62, 7-9.

Daviet, L., and Schalk, M. (2010). Biotechnology in plant essential oil production: progress and perspective in metabolic engineering of the terpene pathway. Flavour Fragr. J. 25, 123-127. doi: 10.1002/ffj.1981
De Luca, V., Salim, V., Atsumi, S. M., and Yu, F. (2012). Mining the biodiversity of plants: a revolution in the making. Science 336, 1658-1661. doi: 10.1126/ science. 1217410

De Oliveira, C. A. F., Corassin, C. H., Corrêa, B., and Oswald, I. P. (2014). "Animal health: Mycotoxins," in Encyclopedia of Agriculture and Food Systems, ed. N. K. Van Alfen (Oxford: Academic Press), 358-377. doi: 10.1016/B978-0444-52512-3.00200-X

Del Pilar Nicasio-Torres, M., Meckes-Fischer, M., Aguilar-Santamaría, L., Garduño-Ramírez, M. L., Chávez-Ávila, V. M., and Cruz-Sosa, F. (2012). Production of chlorogenic acid and isoorientin hypoglycemic compounds in Cecropia obtusifolia calli and in cell suspension cultures with nitrate deficiency. Acta Physiol. Plant. 34, 307-316. doi: 10.1007/s11738-011-0830-9

Dellapenna, D. (2001). Plant metabolic engineering. Plant Physiol. 125, 160-163. doi: 10.1104/pp.125.1.160

Devaux, C. A., Rolain, J.-M., Colson, P., and Raoult, D. (2020). New insights on the antiviral effects of chloroquine against coronavirus: What to expect for COVID-19? Int. J. Antimicrob. Agents 55:105938. doi: 10.1016/j.ijantimicag. 2020.105938

Dyakov, Y. T., Dzhavakhiya, V. G., and Korpela, T. (2007). “Chapter 15 - Molecular basis of plant immunization," in Comprehensive and Molecular Phytopathology, eds Y. T. Dyakov, V. G. Dzhavakhiya, and T. Korpela (Amsterdam: Elsevier), 423-438. doi: 10.1016/B978-044452132-3/50020-1

Faizal, A., and Sari, A. V. (2019). Enhancement of saponin accumulation in adventitious root culture of Javanese ginseng (Talinum paniculatum Gaertn.) through methyl jasmonate and salicylic acid elicitation. Afr. J. Biotechnol. 18, 130-135. doi: 10.5897/AJB2018.16736

Fan, C., Pu, N., Wang, X., Wang, Y., Fang, L., Xu, W., et al. (2008). Agrobacteriummediated genetic transformation of grapevine (Vitis vinifera L.) with a novel stilbene synthase gene from Chinese wild Vitis pseudoreticulata. Plant Cell Tissue Organ Cult. 92, 197-206. doi: 10.1007/s11240-007-9324-2

Fan, H.-H., Wang, L.-Q., Liu, W.-L., An, X.-P., Liu, Z.-D., He, X.-Q., et al. (2020). Repurposing of clinically approved drugs for treatment of coronavirus disease 2019 in a 2019-novel coronavirus-related coronavirus model. Chin. Med. J. 133, 1051-1056. doi: 10.1097/CM9.0000000000000797

Ferner, R. E., and Aronson, J. K. (2020). Chloroquine and hydroxychloroquine in covid-19. BMJ 369:m1432. doi: 10.1136/bmj.m1432

Ferri, M., Tassoni, A., Franceschetti, M., Righetti, L., Naldrett, M. J., and Bagni, N. (2009). Chitosan treatment induces changes of protein expression profile and stilbene distribution in Vitis vinifera cell suspensions. Proteomics 9, 610-624. doi: 10.1002/pmic.200800386

Gandhi, S. G., Mahajan, V., and Bedi, Y. S. (2015). Changing trends in biotechnology of secondary metabolism in medicinal and aromatic plants. Planta 241, 303-317. doi: 10.1007/s00425-014-2232-x

Gantait, S., Mitra, M., and Chen, J.-T. (2020). Biotechnological interventions for ginsenosides production. Biomolecules 10:538. doi: 10.3390/biom1004 0538

Gautret, P., Lagier, J.-C., Parola, P., Hoang, V. T., Meddeb, L., Mailhe, M., et al. (2020). Hydroxychloroquine and azithromycin as a treatment of COVID-19: results of an open-label non-randomized clinical trial. Int. J. Antimicrob. Agents 56:105949. doi: 10.1016/j.ijantimicag.2020.105949

Giovinazzo, G., Ingrosso, I., Paradiso, A., De Gara, L., and Santino, A. (2012). Resveratrol biosynthesis: plant metabolic engineering for nutritional improvement of food. Plant Foods Hum. Nutr. 67, 191-199.

Giri, C. C., and Zaheer, M. (2016). Chemical elicitors versus secondary metabolite production in vitro using Plant Cell, Tissue and Organ Cultures: recent trends and a sky eye view appraisal. Plant Cell Tissue Organ Cult. 126, 1-18. doi: 10.1007/S11240-016-0985-6

Gounaris, Y. (2010). Biotechnology for the production of essential oils, flavours and volatile isolates. A review. Flavour Fragr. J. 25, 367-386. doi: 10.1002/ffj. 1996

György, Z., Tolonen, A., Pakonen, M., Neubauer, P., and Hohtola, A. (2004). Enhancing the production of cinnamyl glycosides in compact callus aggregate cultures of Rhodiola rosea by biotransformation of cinnamyl alcohol. Plant Sci. 166, 229-236. doi: 10.1016/j.plantsci.2003.09.011

Hadwiger, L. A. (2013). Multiple effects of chitosan on plant systems: solid science or hype. Plant Sci. 208, 42-49. doi: 10.1016/j.plantsci.2013.03.007 
Hain, R., Reif, H.-J., Krause, E., Langebartels, R., Kindl, H., Vornam, B., et al. (1993). Disease resistance results from foreign phytoalexin expression in a novel plant. Nature 361, 153-156. doi: 10.1038/361153a0

Halder, M., Sarkar, S., and Jha, S. (2019). Elicitation: a biotechnological tool for enhanced production of secondary metabolites in hairy root cultures. Eng. Life Sci. 19, 880-895. doi: 10.1002/elsc.201900058

Halls, C., and Yu, O. (2008). Potential for metabolic engineering of resveratrol biosynthesis. Trends Biotechnol. 26, 77-81. doi: 10.1016/j.tibtech.2007.11.002

Harrison, C. (2020). Coronavirus puts drug repurposing on the fast track. Nat. Biotechnol. 38, 379-381. doi: 10.1038/d41587-020-00003-1

Hawkins, B. (2007). Plants for Life Medicinal Plant Conservation and Botanic Gardens. Wuhan: BGCI.

Hayashi, H., Fukui, H., and Tabata, M. (1990). Biotransformation of $18 \beta$ glycyrrhetinic acid by cell suspension cultures of Glycyrrhiza glabra. Phytochemistry 29, 2149-2152. doi: 10.1016/0031-9422(90)83026-W

He, Y., Hu, Z., Li, A., Zhu, Z., Yang, N., Ying, Z., et al. (2019). Recent advances in biotransformation of saponins. Molecules 24:2365. doi: 10.3390/ molecules 24132365

Hegazi, G., Ghareb, H., and Gabr, M. (2020). Ephedrine production from suspension cultures of Ephedra alata L. callus. Biotechnologia 101, 25-33. doi: 10.5114/bta.2020.92925

Ho, T.-Y., Wu, S.-L., Chen, J.-C., Li, C.-C., and Hsiang, C.-Y. (2007). Emodin blocks the SARS coronavirus spike protein and angiotensin-converting enzyme 2 interaction. Antiviral Res. 74, 92-101. doi: 10.1016/j.antiviral.2006.04.014

Holopainen, J. K. (2011). Can forest trees compensate for stress-generated growth losses by induced production of volatile compounds? Tree Physiol. 31, 13561377. doi: 10.1093/treephys/tpr111

Huang, X., Yao, J., Zhao, Y., Xie, D., Jiang, X., and Xu, Z. (2016). Efficient rutin and quercetin biosynthesis through flavonoids-related gene expression in Fagopyrum tataricum Gaertn. hairy root cultures with UV-B irradiation. Front. Plant Sci. 7:63. doi: 10.3389/fpls.2016.00063

Hussain, M. S., Fareed, S., Saba Ansari, M., Rahman, A., Ahmad, I. Z., and Saeed, M. (2012). Current approaches toward production of secondary plant metabolites. J. Pharm. Bioallied Sci. 4, 10-20. doi: 10.4103/0975-7406.92725

Jackson, L. A., Anderson, E. J., Rouphael, N. G., Roberts, P. C., Makhene, M., Coler, R. N., et al. (2020). An mRNA Vaccine against SARS-CoV-2 - Preliminary Report. N. Engl. J. Med. 383, 1920-1931. doi: 10.1056/NEJMoa2022483

Jiao, J., Gai, Q.-Y., Wang, W., Luo, M., Zu, Y.-G., Fu, Y.-J., et al. (2016). Enhanced astragaloside production and transcriptional responses of biosynthetic genes in Astragalus membranaceus hairy root cultures by elicitation with methyl jasmonate. Biochem. Eng. J. 105, 339-346. doi: 10.1016/j.bej.2015.10.010

Jiao, J., Gai, Q.-Y., Wang, W., Zang, Y.-P., Niu, L.-L., Fu, Y.-J., et al. (2018). Remarkable enhancement of flavonoid production in a co-cultivation system of Isatis tinctoria L. hairy root cultures and immobilized Aspergillus niger. Ind. Crops Prod. 112, 252-261. doi: 10.1016/j.indcrop.2017.12.017

Kad, A., Pundir, A., and Sood, H. (2018). Elicitation of salidroside under tissue culture conditions in the trans-himalayan plant Rhodiola imbricata. WSEAS Transact. Biol. Biomed. 16, 75-89.

Kannan, N., Manokari, M., and Shekhawat, M. S. (2020). Enhanced production of anthraquinones and phenolic compounds using chitosan from the adventitious roots of Morinda coreia Buck. and Ham. Ind. Crops Prod. 148:112321. doi: 10.1016/j.indcrop.2020.112321

Karuppaiya, P., and Tsay, H. S. (2020). Enhanced production of podophyllotoxin, kaempferol, and quercetin from callus culture of Dysosma pleiantha (Hance) Woodson: An endangered medicinal plant. Biotechnol. Appl. Biochem. 67, 95-104. doi: 10.1002/bab.1810

Karwasara, V. S., Jain, R., Tomar, P., and Dixit, V. K. (2010). Elicitation as yield enhancement strategy for glycyrrhizin production by cell cultures of Abrus precatorius Linn. In Vitro Cell. Dev. Biol. Plant 46, 354-362. doi: 10.1007/ s11627-010-9278-7

Keyaerts, E., Vijgen, L., Maes, P., Neyts, J., and Ranst, M. V. (2004). In vitro inhibition of severe acute respiratory syndrome coronavirus by chloroquine. Biochem. Biophys. Res. Commun. 323, 264-268. doi: 10.1016/j.bbrc.2004. 08.085

Keyaerts, E., Vijgen, L., Pannecouque, C., Van Damme, E., Peumans, W., Egberink, H., et al. (2007). Plant lectins are potent inhibitors of coronaviruses by interfering with two targets in the viral replication cycle. Antiviral Res. 75, 179-187. doi: 10.1016/j.antiviral.2007.03.003
Khan, I., Khan, M. A., Shehzad, M. A., Ali, A., Mohammad, S., Ali, H., et al. (2020). Micropropagation and production of health promoting Lignans in Linum usitatissimum. Plants 9:728. doi: 10.3390/plants9060728

Khan, M. A., Ali, A., Mohammad, S., Ali, H., Khan, T., Jan, A., et al. (2020). Iron nano modulated growth and biosynthesis of steviol glycosides in Stevia rebaudiana. Plant Cell Tissue Organ Cult. 143, 121-130. doi: 10.1007/s11240020-01902-6

Khan, M. A., Khan, T., and Ali, H. (2019a). Plant cell culture strategies for the production of terpenes as green solvents. Ind. Appl. Green Solvents 50, 1-20. doi: 10.21741/9781644900239-1

Khan, M. A., Khan, T., Riaz, M. S., Ullah, N., Ali, H., and Nadhman, A. (2019b). "Plant cell nanomaterials interaction: growth, physiology and secondary metabolism," in Comprehensive Analytical Chemistry, eds S. K. Verma and A. K. Das (Amsterdam: Elsevier), 23-54. doi: 10.1016/bs.coac.2019.04.005

Khan, T., Abbasi, B. H., Khan, M. A., and Azeem, M. (2017). Production of biomass and useful compounds through elicitation in adventitious root cultures of Fagonia indica. Ind. Crops Prod. 108, 451-457. doi: 10.1016/j.indcrop.2017. 07.019

Khan, T., Ullah, M. A., Garros, L., Hano, C., and Abbasi, B. H. (2019c). Synergistic effects of melatonin and distinct spectral lights for enhanced production of anti-cancerous compounds in callus cultures of Fagonia indica. J. Photochem. Photobiol. B Biol. 190, 163-171. doi: 10.1016/j.jphotobiol.2018.10.010

Kim, D., Kim, S., Jeong, I., Kim, J.-B., Lee, G.-J., Kang, S.-Y., et al. (2009). Improvement of ginsenoside production by Panax ginseng adventitious roots induced by $\gamma$-irradiation. Biol. Plant. 53:408. doi: 10.1007/s10535-0090079-y

Kim, D. E., Min, J. S., Jang, M. S., Lee, J. Y., Shin, Y. S., Park, C. M., et al. (2019). Natural bis-benzylisoquinoline alkaloids-tetrandrine, fangchinoline, and cepharanthine, inhibit human coronavirus OC43 infection of MRC-5 human lung cells. Biomolecules 9:696. doi: 10.3390/biom9110696

Kim, D. S., Song, M., Kim, S.-H., Jang, D.-S., Kim, J.-B., Ha, B.-K., et al. (2013). The improvement of ginsenoside accumulation in Panax ginseng as a result of $\gamma$-irradiation. J. Ginseng Res. 37, 332-340. doi: 10.5142/jgr.2013.37.332

Kim, J. Y., Kim, Y. I., Park, S. J., Kim, I. K., Choi, Y. K., and Kim, S.-H. (2018). Safe, high-throughput screening of natural compounds of MERS-CoV entry inhibitors using a pseudovirus expressing MERS-CoV spike protein. Int. J. Antimicrob. Agents 52, 730-732. doi: 10.1016/j.ijantimicag.2018.05.003

Kim, Y.-S., Hahn, E.-J., Murthy, H. N., and Paek, K.-Y. (2004). Effect of polyploidy induction on biomass and ginsenoside accumulations in adventitious roots of ginseng. J. Plant Biol. 47, 356-360. doi: 10.1007/BF03030551

Kusakari, K., Yokoyama, M., and Inomata, S. (2000). Enhanced production of saikosaponins by root culture of Bupleurum falcatum L. using two-step control of sugar concentration. Plant Cell Rep. 19, 1115-1120. doi: 10.1007/ s002990000240

Ledford, H. (2020). Coronavirus breakthrough: dexamethasone is first drug shown to save lives. Nature 582:469. doi: 10.1038/d41586-020-01824-5

Levenson, E., and Howard, J. (2020). What We Know About Moderna's Coronvirus Vaccine and How it Differs From Pfizer's. CNN. Available online at: https://edition.cnn.com/2020/12/17/health/moderna-vaccine-whatwe-know/index.html (accessed February 12, 2021).

Li, S.-Y., Chen, C., Zhang, H.-Q., Guo, H.-Y., Wang, H., Wang, L., et al. (2005). Identification of natural compounds with antiviral activities against SARSassociated coronavirus. Antiviral Res. 67, 18-23. doi: 10.1016/j.antiviral.2005. 02.007

Li, Y.-J., Guo, Y., Yang, Q., Weng, X.-G., Yang, L., Wang, Y.-J., et al. (2015). Flavonoids casticin and chrysosplenol D from Artemisia annua L. inhibit inflammation in vitro and in vivo. Toxicol. Appl. Pharmacol. 286, 151-158. doi: 10.1016/j.taap.2015.04.005

Lin, S.-C., Ho, C.-T., Chuo, W.-H., Li, S., Wang, T. T., and Lin, C.-C. (2017). Effective inhibition of MERS-CoV infection by resveratrol. BMC Infect. Dis. 17:144. doi: 10.1186/s12879-017-2253-8

Lubbe, A., Seibert, I., Klimkait, T., and Van Der Kooy, F. (2012). Ethnopharmacology in overdrive: the remarkable anti-HIV activity of Artemisia annua. J. Ethnopharmacol. 141, 854-859. doi: 10.1016/j.jep.2012.03. 024

Lung, J., Lin, Y. S., Yang, Y. H., Chou, Y. L., Shu, L. H., Cheng, Y. C., et al. (2020). The potential chemical structure of anti-SARS-CoV-2 RNA-dependent RNA polymerase. J. Med. Virol. 92, 693-697. doi: 10.1002/jmv.25761 
Marchev, A. S., Yordanova, Z. P., and Georgiev, M. I. (2020). Green (cell) factories for advanced production of plant secondary metabolites. Crit. Rev. Biotechnol. 40, 443-458. doi: 10.1080/07388551.2020.1731414

Maxmen, A. (2020). More than 80 clinical trials launch to test coronavirus treatments. Nature 578, 347-348. doi: 10.1038/d41586-020-00444-3

Nadeem, M., Ahmad, W., Zahir, A., Hano, C., and Abbasi, B. H. (2019). Salicylic acid-enhanced biosynthesis of pharmacologically important lignans and neo lignans in cell suspension culture of Linum ussitatsimum L. Eng. Life Sci. 19, 168-174. doi: 10.1002/elsc.201800095

Nature. (2020). Redeploying plant defences. Nat. Plants 6:177. doi: 10.1038/ s41477-020-0628-0

Nazir, M., Asad Ullah, M., Mumtaz, S., Siddiquah, A., Shah, M., Drouet, S., et al. (2020). Interactive effect of melatonin and UV-C on phenylpropanoid metabolite production and antioxidant potential in callus cultures of purple basil (Ocimum basilicum L. var. s purpurascens). Molecules 25:1072. doi: 10. 3390/molecules25051072

Olgunsoy, P., Ulusoy, S., and Akçay, U. Ç. (2017). Metabolite production and antibacterial activities of callus cultures from rosa damascena mill. Petals. Marmara Pharm. J. 21, 590-597. doi: 10.12991/marupj.319331

Orihara, Y., and Furuya, T. (1990). Biotransformation of 18ß-glycyrrhetinic acid by cultured cells of Eucalyptus perriniana and Coffea arabica. Phytochemistry 29, 3123-3126. doi: 10.1016/0031-9422(90)80169-H

Osman, N. I., Sidik, N. J., and Awal, A. (2018). Efficient enhancement of gallic acid accumulation in cell suspension cultures of Barringtonia racemosa L. by elicitation. Plant Cell Tissue Organ Cult. 135, 203-212. doi: 10.1007/s11240018-1456-z

Park, J.-Y., Jeong, H. J., Kim, J. H., Kim, Y. M., Park, S.-J., Kim, D., et al. (2012a). Diarylheptanoids from Alnus japonica inhibit papain-like protease of severe acute respiratory syndrome coronavirus. Biol. Pharm. Bull. 35, 2036-2042. doi: 10.1248/bpb.b12-00623

Park, J.-Y., Kim, J. H., Kim, Y. M., Jeong, H. J., Kim, D. W., Park, K. H., et al. (2012b). Tanshinones as selective and slow-binding inhibitors for SARS-CoV cysteine proteases. Bioorg. Med. Chem. 20, 5928-5935. doi: 10.1016/j.bmc.2012. 07.038

Park, J.-Y., Ko, J.-A., Kim, D. W., Kim, Y. M., Kwon, H.-J., Jeong, H. J., et al. (2016). Chalcones isolated from Angelica keiskei inhibit cysteine proteases of SARS-CoV. J. Enzyme Inhib. Med. Chem. 31, 23-30. doi: 10.3109/14756366. 2014.1003215

Patil, R. A., Lenka, S. K., Normanly, J., Walker, E. L., and Roberts, S. C. (2014). Methyl jasmonate represses growth and affects cell cycle progression in cultured Taxus cells. Plant Cell Rep. 33, 1479-1492. doi: 10.1007/s00299-014-1632-5

Pavlov, A., and Bley, T. (2018). Bioprocessing of Plant in Vitro Systems. Berlin: Springer. doi: 10.1007/978-3-319-54600-1

PMI (2020). Medicago Develops a Plant-Based Vaccine for Coronavirus. Philip Morris International. Available online at: https://www.pmi.com/media-center/ news/medicago-develops-a-plant-based-vaccine-for-coronavirus (accessed February 12, 2021).

Pourebad, N., Motafakkerazad, R., Kosari-Nasab, M., Akhtar, N. F., and Movafeghi, A. (2015). The influence of TDZ concentrations on in vitro growth and production of secondary metabolites by the shoot and callus culture of Lallemantia iberica. Plant Cell Tissue Organ Cult. 122, 331-339. doi: 10.1007/ s11240-015-0769-4

Ptak, A., Morañska, E., Saliba, S., Zieliñski, A., Simlat, M., and Laurain-Mattar, D. (2017). Elicitation of galanthamine and lycorine biosynthesis by Leucojum aestivum L. and L. aestivum 'Gravety Giant' plants cultured in bioreactor RITAS. Plant Cell Tissue Organ Cult. 128, 335-345. doi: 10.1007/s11240-016$1113-3$

Ramirez-Estrada, K., Vidal-Limon, H., Hidalgo, D., Moyano, E., Golenioswki, M., Cusidó, R. M., et al. (2016). Elicitation, an effective strategy for the biotechnological production of bioactive high-added value compounds in plant cell factories. Molecules 21, 182-182. doi: 10.3390/molecules 21020182

Razavizadeh, R., Adabavazeh, F., and Komatsu, S. (2020). Chitosan effects on the elevation of essential oils and antioxidant activity of Carum copticum L. seedlings and callus cultures under in vitro salt stress. J. Plant Biochem. Biotechnol. 29, 473-483. doi: 10.1007/s13562-020-00560-1

Roberts, S. C. (2007). Production and engineering of terpenoids in plant cell culture. Nat. Chem. Biol. 3, 387-395. doi: 10.1038/nchembio.2007.8
Ryang, J., Yan, Y., Song, Y., Liu, F., and Ng, T. B. (2019). Anti-HIV, antitumor and immunomodulatory activities of paclitaxel from fermentation broth using molecular imprinting technique. AMB Express 9:194. doi: 10.1186/s13568-0190915-1

Ryu, Y. B., Jeong, H. J., Kim, J. H., Kim, Y. M., Park, J.-Y., Kim, D., et al. (2010a). Biflavonoids from Torreya nucifera displaying SARS-CoV 3CLpro inhibition. Bioorg. Med. Chem. 18, 7940-7947. doi: 10.1016/j.bmc.2010.09.035

Ryu, Y. B., Park, S.-J., Kim, Y. M., Lee, J.-Y., Seo, W. D., Chang, J. S., et al. (2010b). SARS-CoV 3CLpro inhibitory effects of quinone-methide triterpenes from Tripterygium regelii. Bioorg. Med. Chem. Lett. 20, 1873-1876. doi: 10. 1016/j.bmcl.2010.01.152

Saeed, S., Ali, H., Khan, T., Kayani, W., and Khan, M. A. (2017). Impacts of methyl jasmonate and phenyl acetic acid on biomass accumulation and antioxidant potential in adventitious roots of Ajuga bracteosa Wall ex Benth., a high valued endangered medicinal plant. Physiol. Mol. Biol. Plants 23, 229-237. doi: 10. 1007/s12298-016-0406-7

Sajjalaguddam, R. R., and Paladugu, A. (2015). Phenylalanine enhances Quercetin content in In vitro cultures of Abutilon indicum L. J. Appl. Pharm. Sci. 5, 080-084. doi: 10.7324/JAPS.2015.501014

Santoro, V. M., Nievas, F. L., Zygadlo, J. A., Giordano, W. F., and Banchio, E. (2013). Effects of growth regulators on biomass and the production of secondary metabolites in peppermint (Mentha pi-perita) micropropagated in vitro. Am. J. Plant Sci. 4, 49-55. doi: 10.4236/ajps.2013.45A008

Santos, P. M., Figueiredo, A. C., Oliveira, M. M., Barroso, J., Pedro, L. G., Deans, S. G., et al. (1998). Essential oils from hairy root cultures and from fruits and roots of Pimpinella anisum. Phytochemistry 48, 455-460. doi: 10.1016/S00319422(98)00022-3

Schmitt, J., and Petersen, M. (2002). Influence of methyl jasmonate and coniferyl alcohol on pinoresinol and matairesinol accumulation in a Forsythiax intermedia suspension culture. Plant Cell Rep. 20, 885-890.

Schoeman, D., and Fielding, B. C. (2019). Coronavirus envelope protein: current knowledge. Virol. J. 16:69.

Shaikh, S., Shriram, V., Khare, T., and Kumar, V. (2020). Biotic elicitors enhance diosgenin production in Helicteres isora L. suspension cultures via up-regulation of CAS and HMGR genes. Physiol. Mol. Biol. Plants 26, 593-604.

Shakya, P., Marslin, G., Siram, K., Beerhues, L., and Franklin, G. (2019). Elicitation as a tool to improve the profiles of high-value secondary metabolites and pharmacological properties of Hypericum perforatum. J. Pharm. Pharmacol. 71, $70-82$.

Shen, X., Du, Q., Xu, Y., and Lu, Y. J. E. J. O. B. (2012). Stimulation of transresveratrol biosynthesis in Vitis vinifera cv. Kyoho cell suspension cultures by 2, 3-dihydroxypropyl jasmonate elicitation. Electron. J. Biotechnol. 15:3.

Shi, L., Wang, C., Zhou, X., Zhang, Y., Liu, Y., and Ma, C. (2013). Production of salidroside and tyrosol in cell suspension cultures of Rhodiola crenulata. Plant Cell Tissue Organ Cult. 114, 295-303.

Shintani, D., and Dellapenna, D. (1998). Elevating the vitamin E content of plants through metabolic engineering. Science 282, 2098-2100.

Shrestha, A., Pandey, R. P., and Sohng, J. K. (2019). Biosynthesis of resveratrol and piceatannol in engineered microbial strains: achievements and perspectives. Appl. Microbiol. Biotechnol. 103, 2959-2972.

Skrzypczak-Pietraszek, E., Piska, K., and Pietraszek, J. (2018). Enhanced production of the pharmaceutically important polyphenolic compounds in Vitex agnus castus L. shoot cultures by precursor feeding strategy. Eng. Life Sci. 18, 287-297.

Srivastava, M., Singh, G., Sharma, S., Shukla, S., and Misra, P. (2019). Elicitation enhanced the yield of glycyrrhizin and antioxidant activities in hairy root cultures of Glycyrrhiza glabra L. J. Plant Growth Regul. 38, 373-384.

Stark-Lorenzen, P., Nelke, B., Hänßler, G., Mühlbach, H., and Thomzik, J. (1997). Transfer of a grapevine stilbene synthase gene to rice (Oryza sativa L.). Plant Cell Rep. 16, 668-673.

Teptat, P., Tansakul, P., and Sakunphueak, A. (2020). Effects of Sequential and Simultaneous Double Elicitation on Aloe-Emodin Production in Cassia Tora Root Cultures. Available online at: https://www.researchsquare.com/article/rs38327/v1 (accessed September 15, 2020).

Thanh Le, T., Andreadakis, Z., Kumar, A., Gómez Román, R., Tollefsen, S., Saville, M., et al. (2020). The COVID-19 vaccine development landscape. Nat. Rev. Drug Discov. 19, 305-306. 
Tirillini, B., Ricci, A., Pintore, G., Chessa, M., and Sighinolfi, S. (2006). Induction of hypericins in Hypericum perforatum in response to chromium. Fitoterapia 77, 164-170.

Vafadar, F., Amooaghaie, R., Ehsanzadeh, P., Ghanadian, M., Talebi, M., and Ghanati, F. (2020). Melatonin and calcium modulate the production of rosmarinic acid, luteolin, and apigenin in Dracocephalum kotschyi under salinity stress. Phytochemistry 177:112422.

Veerashree, V., Anuradha, C., and Kumar, V. (2012). Elicitor-enhanced production of gymnemic acid in cell suspension cultures of Gymnema sylvestre R. Br. Plant Cell Tissue Organ Cult. 108, 27-35.

Verpoorte, R., Contin, A., and Memelink, J. (2002). Biotechnology for the production of plant secondary metabolites. Phytochem. Rev. 1, 13-25.

Wang, M., Cao, R., Zhang, L., Yang, X., Liu, J., Xu, M., et al. (2020). Remdesivir and chloroquine effectively inhibit the recently emerged novel coronavirus (2019-nCoV) in vitro. Cell Res. 30, 269-271.

Wang, W., Zhao, Z.-J., Xu, Y., Qian, X., and Zhong, J.-J. (2006). Efficient induction of ginsenoside biosynthesis and alteration of ginsenoside heterogeneity in cell cultures of Panax notoginseng by using chemically synthesized 2-hydroxyethyl jasmonate. Appl. Microbiol. Biotechnol. 70, 298-307.

Weathers, P. J., Towler, M. J., and Xu, J. (2010). Bench to batch: advances in plant cell culture for producing useful products. Appl. Microbiol. Biotechnol. 85, 1339-1351.

Wen, C.-C., Kuo, Y.-H., Jan, J.-T., Liang, P.-H., Wang, S.-Y., Liu, H.-G., et al. (2007). Specific plant Terpenoids and Lignoids possess potent antiviral activities against severe acute respiratory syndrome coronavirus. J. Med. Chem. 50, 4087-4095.

Wilczañska-Barska, A., Królicka, A., Głód, D., Majdan, M., Kawiak, A., and KrauzeBaranowska, M. (2012). Enhanced accumulation of secondary metabolites in hairy root cultures of Scutellaria lateriflora following elicitation. Biotechnol. Lett. 34, 1757-1763.

Wink, M. (2020). Potential of DNA intercalating alkaloids and other plant secondary metabolites against SARS-CoV-2 causing COVID-19. Diversity $12: 175$.

Wongwicha, W., Tanaka, H., Shoyama, Y., and Putalun, W. (2011). Methyl jasmonate elicitation enhances glycyrrhizin production in Glycyrrhiza inflata hairy roots cultures. Z. Naturforschung C J. Biosci. 66, 423-428.

Worldometer (2020). Coronavirus. Available online at: https://www.worldometers. info/coronavirus/ (accessed November 14, 2020).
Wu, C.-Y., Jan, J.-T., Ma, S.-H., Kuo, C.-J., Juan, H.-F., Cheng, Y.-S. E., et al. (2004). Small molecules targeting severe acute respiratory syndrome human coronavirus. Proc. Natl. Acad. Sci. U.S.A. 101, 10012-10017.

Wurtzel, E. T., and Kutchan, T. M. (2016). Plant metabolism, the diverse chemistry set of the future. Science 353, 1232-1236.

Yang, Q.-Y., Tian, X.-Y., and Fang, W.-S. (2007). Bioactive coumarins from Boenninghausenia sessilicarpa. J. Asian Nat. Prod. Res. 9, 59-65.

Yarmolinsky, L., Huleihel, M., Zaccai, M., and Ben-Shabat, S. (2012). Potent antiviral flavone glycosides from Ficus benjamina leaves. Fitoterapia 83, 362367.

Ye, X., Al-Babili, S., Klöti, A., Zhang, J., Lucca, P., Beyer, P., et al. (2000). Engineering the provitamin A ( $\beta$-carotene) biosynthetic pathway into (carotenoid-free) rice endosperm. Science 287, 303-305.

Yi, L., Li, Z., Yuan, K., Qu, X., Chen, J., Wang, G., et al. (2004). Small molecules blocking the entry of severe acute respiratory syndrome coronavirus into host cells. J. Virol. 78, 11334-11339.

Yu, K.-W., Gao, W., Hahn, E.-J., and Paek, K.-Y. (2002). Jasmonic acid improves ginsenoside accumulation in adventitious root culture of Panax ginseng CA Meyer. Biochem. Eng. J. 11, 211-215.

Yu, M.-S., Lee, J., Lee, J. M., Kim, Y., Chin, Y.-W., Jee, J.-G., et al. (2012). Identification of myricetin and scutellarein as novel chemical inhibitors of the SARS coronavirus helicase, nsP13. Bioorg. Med. Chem. Letters 22, 4049-4054.

Yu, Y., Zhang, W.-B., Li, X.-Y., Piao, X.-C., Jiang, J., and Lian, M.-L. (2016). Pathogenic fungal elicitors enhance ginsenoside biosynthesis of adventitious roots in Panax quinquefolius during bioreactor culture. Ind. Crops Prod. 94, $729-735$.

Conflict of Interest: The authors declare that the research was conducted in the absence of any commercial or financial relationships that could be construed as a potential conflict of interest.

Copyright (c) 2021 Khan, Khan, Karam, Ullah, Mashwani and Nadhman. This is an open-access article distributed under the terms of the Creative Commons Attribution License (CC BY). The use, distribution or reproduction in other forums is permitted, provided the original author(s) and the copyright owner(s) are credited and that the original publication in this journal is cited, in accordance with accepted academic practice. No use, distribution or reproduction is permitted which does not comply with these terms. 